\title{
Mechanisms of Oxidation Degradation of Cr12 Roller Steel during Thermal Fatigue Tests
}

\author{
David Bombač ${ }^{1,2, *} \mathbb{1}$, Marius Gintalas ${ }^{3,4,5}$, Goran Kugler ${ }^{1}$ and Milan Terčelj ${ }^{1, *}$ \\ 1 Faculty of Natural Sciences and Engineering, University of Ljubljana, 1000 Ljubljana, Slovenia; \\ goran.kugler@ntf.uni-lj.si \\ 2 Department of Materials Science and Metallurgy, University of Cambridge, Cambridge CB3 OFS, UK \\ 3 Department of Mechanical and Aerospace Engineering, NSIRC, Brunel University London, \\ Cambridge CB21 6AL, UK; marius.gintalas@brunel.ac.uk \\ 4 Mechanical and Marine Engineering Laboratory, Marine Research Institute, Klaipeda University, \\ 92294 Klaipeda, Lithuania \\ 5 Faculty of Marine Technology and Natural Sciences, Klaipèda University, 91225 Klaipèda, Lithuania \\ * Correspondence: david.bombac@ntf.uni-lj.si (D.B.); milan.tercelj@ntf.uni-lj.si (M.T.); \\ Tel.: +386-1-2000-454 (D.B.); +386-1-2000-462 (M.T.)
}

Received: 3 March 2020; Accepted: 24 March 2020; Published: 28 March 2020

\begin{abstract}
Degradation by the penetration of oxidation into the Cr12 roller steel is evaluated during thermal fatigue tests in the laboratory in the temperature range of $500-700^{\circ} \mathrm{C}$. A qualitative assessment is carried out with regard to the thermal load, the microstructure and the test temperature. The results show that the specific properties of the microstructure with respect to thermal stress and temperature have a significant influence on the oxidation behavior as well as on the crack propagation mode and crack growth. The conditions that lead to an increase in the oxidation rate and thus to premature and sudden local chipping of the roll surface layer are analyzed and explained.
\end{abstract}

Keywords: steel; thermal cycling; oxidation; interfaces; effects of strain

\section{Introduction}

Hot rolling is the most important bulk forming process. The central tools in this mass forming process are work rolls (steel rollers), which account for up to $15 \%$ of the manufacturing costs $[1,2]$. During operation, rollers are exposed to a deterioration of the surface layer, which affects the surface quality of the rolled products. High manufacturing costs make any attempts to increase the operating time of the rolls and improve the surface quality of the rolled products enticing [2-4]. The oxidation process of rolls has a strong influence on the complex degradation process of the roll surface layer [4-13]. The degradation of the roller surface is related to the microstructure, the temperature and the thermal stresses acting on it. The oxidation behavior of the roll surface is an important degradation mechanism. It is generally very complex, as temperature, time, environmental conditions and microstructure are intertwined [3,5-34]. The oxidation behavior of roller material at high temperatures was investigated by oxidation studies $[4,15,22,23,28,34-38]$, tribological tests $[3,9-11,14,16,25,26,33,35,39-57]$ and thermal fatigue tests $[5,6,12,29-31]$. The tribological tests were performed with disc-on-disc tests [3,9-11,16,24$26,32,35,39-50,57]$ or pin-on-disc tests $[14,16,28,51-55]$. The aim was to evaluate: the wear behavior of cast, high-speed steel roller material; lubricants; the influence of $\mathrm{C}$ and $\mathrm{Cr}$ contents on wear resistance and surface roughness; and the wear and friction behavior of high speed steel, ledeburitic steel and cast iron with high $\mathrm{Cr}$ content, etc. The tribological tests were performed at high temperatures and under isothermal conditions.

Hanlon et al. [45] and Molinari et al. [15] observed the oxide penetration into the material at the carbide/matrix interface. However, their studies do not focus on oxidation penetration in connection 
with microstructure, temperature and thermal stress. In addition, Lao et al. [27] argue that the condition under isothermal testing in the highly plastic deformed area during sliding wear is not comparable with the behavior during hot rolling. Since these interrelationships are not sufficiently explained, it is essential to carry out research in this area in order to improve our knowledge of the aforementioned interrelated influences and mechanisms.

Numerous oxidation studies have been performed in different atmospheres at high temperatures [ 4 , 15,22,23,28,34,36-38]. Different oxidation rates of the matrix and the carbides were determined depending on the test temperature, the material, the carbide properties and the atmosphere (oxidation conditions). Contrary to the general assumption, Kim et al. [34] argue that carbides oxidize faster than the matrix in a dry atmosphere and that the oxides on the surface of the oxidized matrix become larger. In addition, different oxidation rates were observed for the different carbide types in the matrix, which is the basis for the formation of relatively small oxidation tongues. In the studies [5,6,12,29-31] thermal fatigue tests were used to demonstrate that oxidation accelerates crack growth and other degradation processes (i.e., chipping and spalling). However, the oxidation penetration was not investigated. Colas et al. [7] showed an accentuated oxidation penetration in high $\mathrm{Cr}$ roller material, but they did not explain the reasons for this behavior. This can be attributed to a strong water cooling of the heated material. Garza-Montes-de-Oca et al. [39] showed that an increased presence of water leads to an increased oxidation rate.

The lack of results that explain the degradation processes due to oxidation penetration can be attributed to the laboratory test conditions used. In real industrial settings, temperatures during heating reach or even exceed $700{ }^{\circ} \mathrm{C}$. This is followed by intensive water cooling, generating a large amount of steam. Conditions found in the laboratory often do not reproduce the severe conditions found in industry. Our thermal fatigue testing setup [5,6], has the advantage of an extremely precise temperature control with computer controlled heating and cooling, resulting in a constant temperature field of all cycles from the first to the last. This enabled the repeatability of thermal fatigue tests, wherein quantitative analysis of degradation by thermal cycles showed that oxidation penetration can have a significant influence on the degradation progress of the roller material surface. Therefore, it is important to analyze the behavior of the oxidation penetration in detail with regard to thermal stresses, microstructure and test temperature.

In this paper missing knowledge about oxidation penetration in relation to microstructural properties, test temperature and thermal stresses that influence the subsequent spalling of the roller material are presented, analyzed and discussed. The qualitative analysis of the oxidation behavior and the relationship with the microstructure, the test temperature and the numerically determined thermal stresses was carried out with the aim of better understanding the relationships between oxidation, microstructure and thermal stress states.

\section{Materials and Methods}

The material used in this study was a centrifugally cast roller shell of a high $\mathrm{Cr}$ steel with chemical composition given in Table 1. Thermal fatigue tests were conducted using the Gleeble 1500D (Dynamic Systems Inc., Poestenkill, NY, USA) thermomechanical simulator at three maximum test temperatures $\left(500,600\right.$ and $\left.700{ }^{\circ} \mathrm{C}\right)$ and a finite number of thermal cycles $(200,500,1000$ and 2500 cycles) for each test temperature. Conductive heating and water cooling by the borehole sample were carried out cyclically according to a temperature program that replicates the conditions obtained on the roll surface during hot rolling. A detailed description of the test rig is given in [5], while detailed qualitative and quantitative properties of thermal fatigue resistance for the same material are given in [6].

Table 1. Chemical composition of high Cr roller steel in wt \% used in study.

\begin{tabular}{cccccccccc}
\hline C & Si & Mn & Cr & Mo & Ni & V & Co & S & P \\
\hline 1.651 & 0.662 & 0.731 & 11.282 & 1.171 & 1.941 & 0.262 & 0.017 & 0.009 & 0.017 \\
\hline
\end{tabular}


After the thermal fatigue test, the working lengths of each specimen were first cut in the axial direction through the center and one half also in the radial direction for microscopy. The characterization of cracks was focused within the working length of the specimen. Optical microscopy (Zeiss AXIO Imager.A1m, Carl Zeiss Microscopy GmbH, Jena, Germany) and scanning electron microscopy (JEOL 5610, JEOL Ltd., Tokyo, Japan and FEI Nova NanoSEM, FEI Europe B.V., Eindhoven, Netherlands) were used to observe the microstructure and the damage developed after a finite number of thermal cycles. The surfaces for microstructural evaluation were ground, polished and etched with 3 vol. \% Nital solution. The SEM microscopy was combined with the attached energy dispersive X-ray spectroscopy (EDX) for elemental mapping of the microstructure.

\section{Results}

\subsection{Stress Distribution during Thermal Fatigue Cycle}

The elastic stress distribution during the thermal fatigue cycle was determined by a finite element model created in the Abaqus 2018 (Dassault Systèmes Simulia Corp., Johnston, RI, USA) software. The purposes of the finite element analysis were to determine the stress distributions in the samples under thermal load and to find out which stress component was the strongest and could possibly contribute to crack initiation. The finite element mesh is shown in Figure 1a, and it is a borehole sample with an outer diameter of $8 \mathrm{~mm}$ and a wall thickness of $2 \mathrm{~mm}$ at the measurement cross gauge section. The diameter of the inner bore is $4 \mathrm{~mm}$.

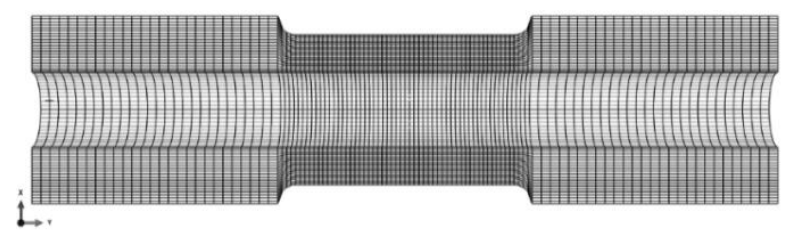

(a)

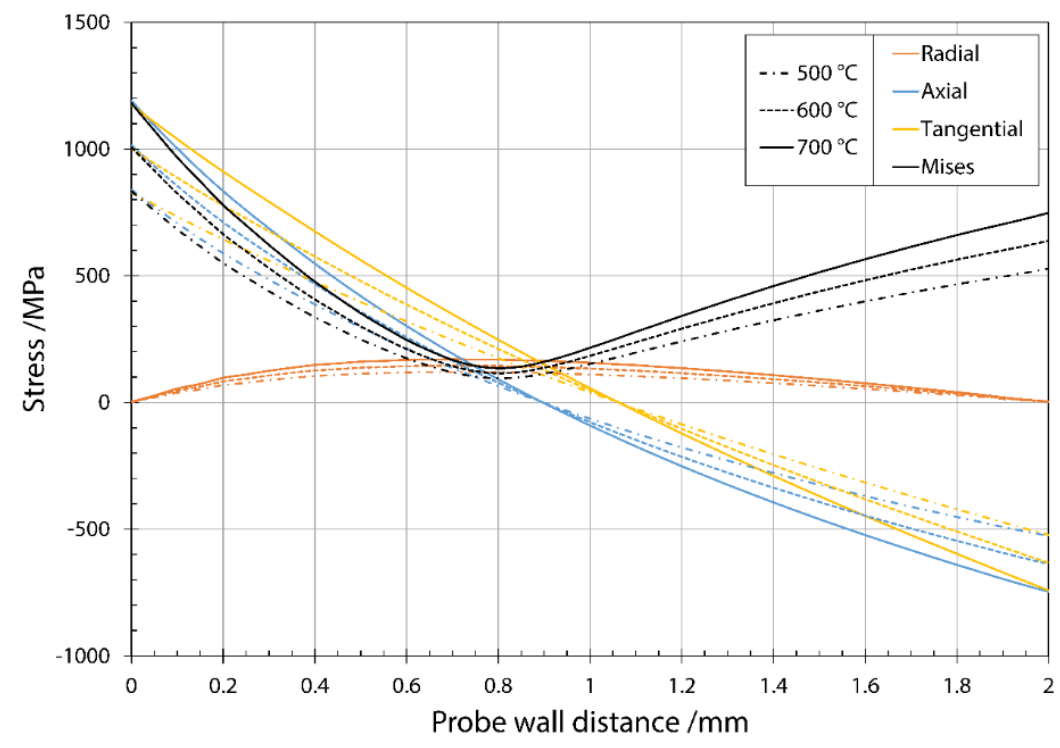

(b)

Figure 1. (a) Meshed finite element model of the sample, and (b) stress distribution through the sample wall at $700{ }^{\circ} \mathrm{C}$ (solid line), $600{ }^{\circ} \mathrm{C}$ (dashed line) and $500{ }^{\circ} \mathrm{C}$ (dashed dotted line).

Steady state coupled displacement-temperature analysis was carried out. This type of analysis allows one to solve the displacement field as a result of the applied temperature. In the model, the temperature was applied as a boundary condition to the outer and inner surfaces of the sample. 
The inner and outer surfaces were subjected to a temperature boundary condition of $20^{\circ} \mathrm{C}$ and a test temperature $\left(500,600\right.$ and $\left.700{ }^{\circ} \mathrm{C}\right)$. The movement of the probe was not restricted in any direction. In the model the quadratically coupled temperature-displacement element type C3D20T was used. The material constants used were as follows: modulus of elasticity $200 \mathrm{GPa}$, Poisson's ratio 0.3, coefficient of thermal expansion $11 \times 10^{-6} \mathrm{~K}^{-1}$, coefficient of thermal conductivity $26 \mathrm{Wm}^{-1} \mathrm{~K}^{-1}$, specific heat $460 \mathrm{Jm}^{-1} \mathrm{~K}^{-1}$ and density $7800 \mathrm{~kg} \mathrm{~m}^{-3}$.

The stress values along the wall thickness were extracted using a cylindrical coordinate system, where the $x$-axis corresponds to the radial direction, the $y$-axis to the axial and the $z$-axis to the tangential (cf. Figure 1a). The sample wall was divided into 20 elements with a uniform thickness of $100 \mu \mathrm{m}$. By selecting the fully integrated element type C3D20T, the center plane of each element is also available for stress extraction. It enabled the extraction of stress values at element nodes located at $50 \mu \mathrm{m}$. The results obtained for stress are summarized in Figure $1 \mathrm{~b}$.

Radial stresses reached a maximum value of $170 \mathrm{MPa}$ at a temperature of $700{ }^{\circ} \mathrm{C}$ at the depth of $700 \mu \mathrm{m}$. Another important finding is that longitudinal stresses on the inner surface of the specimen are positive and generate stress forces, which primarily contributes to crack initiation. The maximum axial stress has a value of $1180 \mathrm{MPa}$ on the inner surface. At the depth of $900 \mu \mathrm{m}$ the axial stresses change their orientation and become compressive. The results obtained show that there are favorable conditions for the initiation of surface or near-surface cracks. High axial stresses contribute to the initiation of transverse cracks and radial stresses to the initiation of longitudinal cracks. In the earlier work of the same authors [6] it was shown that transverse cracks are apparently more severe.

\subsection{Initial Microstructure}

The analysis of the initial microstructure of the same material was described in detail in reference [6]. To summarize the published results, quantitative metallography of roller material with high $\mathrm{Cr}$ content yielded 15.46 vol. $\% \mathrm{M}_{7} \mathrm{C}_{3}$ and 1.41 vol. $\% \mathrm{M}_{2} \mathrm{C}$ carbides and a measured hardness of $601 \pm 10 \mathrm{HV}_{10}$. Based on these results, Figure 2a,b shows a backscatter secondary electron (BSE) micrograph and the elemental distribution of Mo. Building upon XRD analysis presented in the previous study [6], EDX chemical mapping analysis helped to identify Mo-based carbides identified as $\mathrm{M}_{2} \mathrm{C}$ (cf. Figure $2 \mathrm{~b}$ ). Distribution of Mo shows an areas enriched with Mo in carbides.

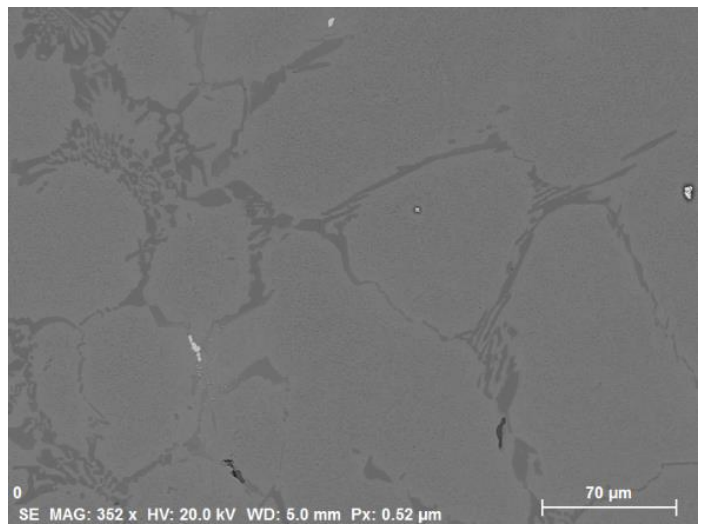

(a)

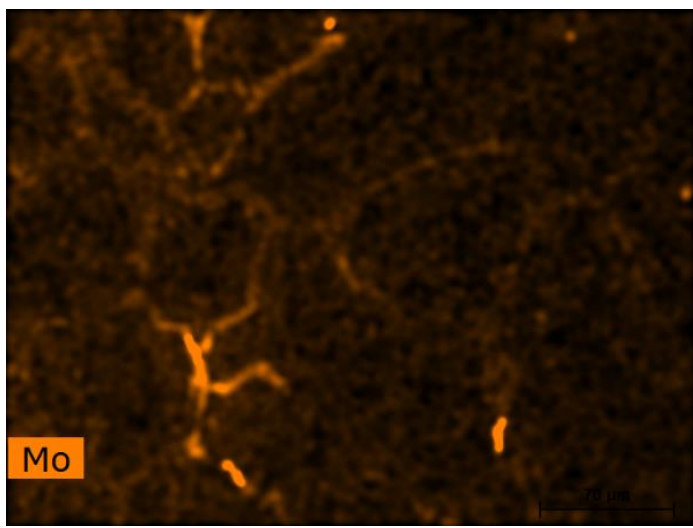

(b)

Figure 2. Initial Cr12 roller steel microstructure: (a) backscatter secondary electron (BSE) micrograph; (b) elemental distribution of Mo.

The approximate chemical compositions of the carbides present in the roller material, as determined by EDX, are shown in Table 2. Reduced Cr content was observed in a narrow band approximately $4 \mu \mathrm{m}$ wide adjacent to the carbide/matrix boundary for the primary carbide shown in Figure 3a and the line distribution of the elements in Figure 3b. Compared to an approximate Cr content of 7-9 wt. \% elsewhere in the matrix, the Cr content within this band was measured at only 4-5 wt. \% (see Table 2). 
Similar results were obtained for the eutectic carbide matrix (see Figure $3 c, d$ ). It is also worth noting that the detected content of Mo in primary carbides (3-8 wt. \%) is increased compared to the content in eutectic carbides (2.1-2.9 wt. \%). On the other hand, the $\mathrm{Cr}$ content in primary carbides is slightly lower (42-50 wt. \%) compared to the content in eutectic carbides (44-52 wt. \%). The values obtained for the $\mathrm{V}$ content in eutectic and primary carbides were in the range of $1.5-1.9 \%$ by weight, while the $\mathrm{V}$ content in the matrix was about $0.1 \%$ by weight (see Table 2 ).

Table 2. Approximate range of elemental content for primary and eutectic carbides, matrix and carbide/matrix band in wt. \%.

\begin{tabular}{cccc}
\hline Microstructural Feature & Cr & Mo & V \\
\hline Primary $\mathrm{M}_{7} \mathrm{C}_{3}$ & $42-50$ & $3-8$ & $1.5-1.9$ \\
Eutectic $\mathrm{M}_{7} \mathrm{C}_{3}$ & $44-52$ & $2.1-2.9$ & $1.5-1.9$ \\
$\mathrm{Mo}_{2} \mathrm{C}$ & $4-7$ & $50-56$ & $0.4-0.7$ \\
$\mathrm{Matrix}_{\text {Carbide/matrix band }}$ & $7-9$ & $0.45-0.75$ & $0.1-0.12$ \\
& $4-5$ & $0.45-0.7$ & - \\
\hline
\end{tabular}

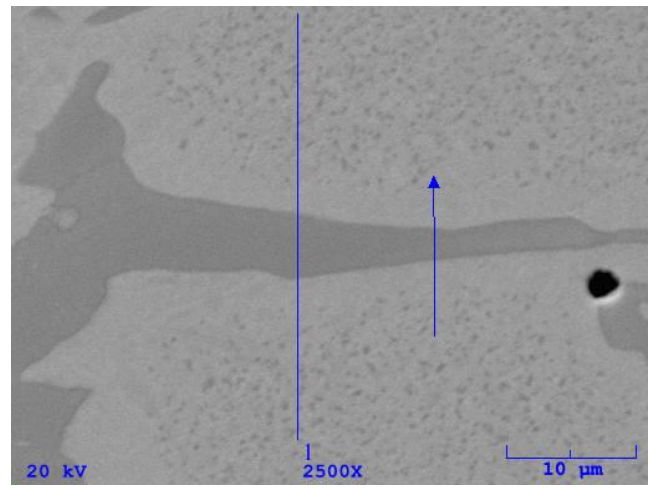

(a)

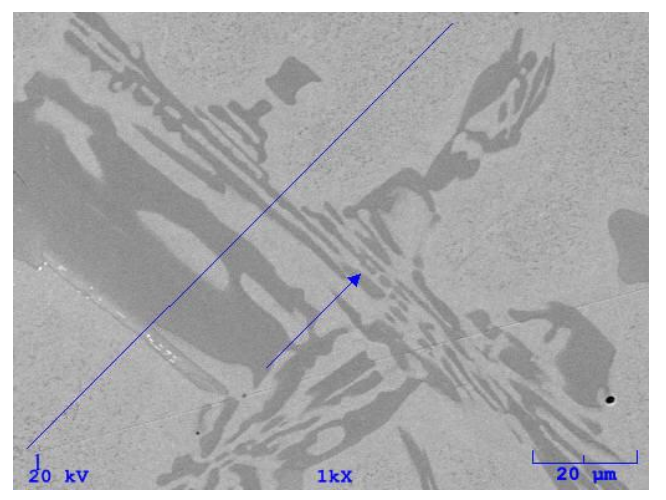

(c)

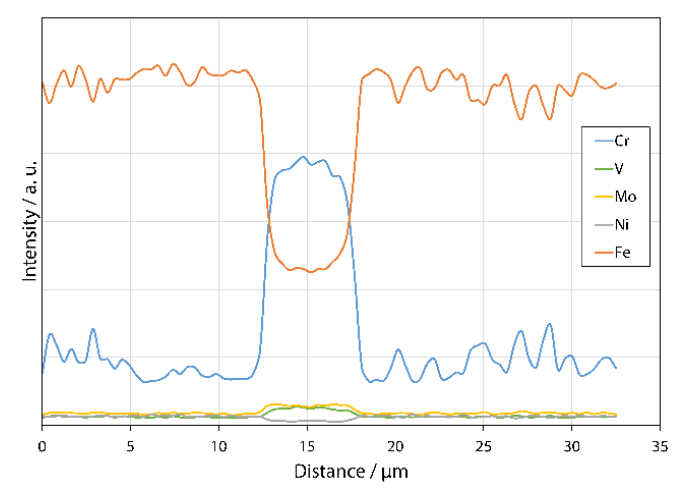

(b)

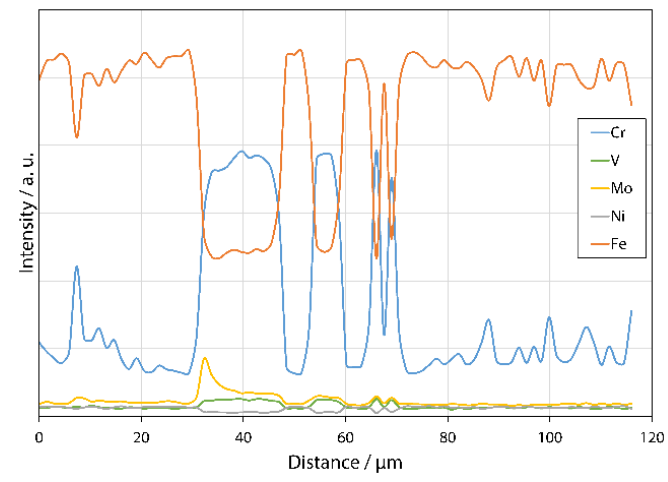

(d)

Figure 3. BSE micrograph and elemental line distributions of $\mathrm{Cr}, \mathrm{Mo}, \mathrm{V}, \mathrm{Ni}$ and $\mathrm{Fe}$ in matrix and carbides: (a) primary carbides, (b) line distribution of elements across primary carbides, (c) eutectic carbides and (d) line distribution of elements across eutectic carbides.

\subsection{Oxidation Behaviour and Its Relationship between Microstructure, Thermal Stress and Temperature}

With regard to the observed oxidation behavior during thermal fatigue testing of the roller material made of high $\mathrm{Cr}$ steel, the following properties are relevant; (i) chemical compositions of primary and eutectic carbides, matrix material, band at the carbide/matrix interface adjacent to primary and eutectic carbides; oxidation progress; (ii) sizes, shapes and orientations of the carbides; their crushing and cracking; crack propagation direction; oxidation behavior at high thermal stresses and (iii) oxidation behavior at low thermal stresses; (iv) direction of the applied effective thermal stress and 
oxidation direction in the matrix; (v) microcracks around the crack tip and oxidation of the crack tip; (vii) uncracked eutectic carbides and oxidation progress (oxidation of carbides or eutectic matrix); (viii) cracked eutectic carbides and oxidation progress; (ix) orientation of eutectic carbide lamellae, thermal stress and oxidation progress; $(x)$ temperature influence on oxidation; (xi) properties of eutectic and primary carbides (arrangement, orientation, size, shape) and cases of significant oxidation area.

During thermal fatigue, the samples were cooled with water. Thus the current test approaches the conditions that occur on the surface of work rolls in rolling mills. Furthermore, it allows the observation of the particularly pronounced oxidation cases presented in this study and enabled us to explain the wear behavior.

\subsubsection{Oxidation Behavior of Uncracked Carbides}

The first interesting case observed was the oxidation of material between the islands of the eutectic carbide cluster. The eutectic cluster shown in Figure $4 \mathrm{a}$ is located about $400 \mu \mathrm{m}$ below the cooled surface. The results of the FEM simulations show that the applied thermal stress (axial) during the temperature changes at this depth is $1180 \mathrm{MPa}$ at $700^{\circ} \mathrm{C}$. Figure 4 a shows that after 2500 thermal cycles a partial oxidation of the matrix between eutectic carbides cluster occurred as a result of thermal stress. However, the carbide lamellae of the carbides are not cracked and no oxidation of the carbides was observed, at least in the central part. However, this happened on a small area, as can be seen in the lower part of the eutectic carbide cluster. The element maps in Figure $4 b, c$ show the distributions of $\mathrm{Cr}$ and Mo. Additional confirmation of the oxidized matrix is shown with the distribution of oxygen in Figure 4d. Qualitatively, the oxidation rate between carbides and matrix can be estimated by detailed examination of the superimposed Figure $4 \mathrm{a}, \mathrm{d}$. Oxidation occurs first in the narrow band at the carbide/matrix interface, whereas eutectic carbides are not oxidized. In addition, a small area in the lower and slightly right part of the eutectic in Figure 4a shows complete oxidation (see Figure 4d), in which matrix and carbides are oxidized. From this it can be confirmed that the oxidation starts in the matrix and has a higher rate compared to the carbide. This finding is important and helps to explain the changes required at the transition from the carbide pathway to the matrix pathway.

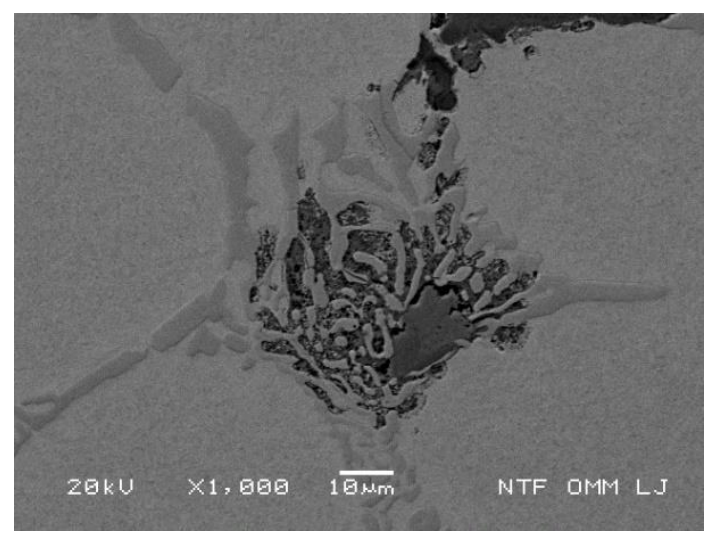

(a)

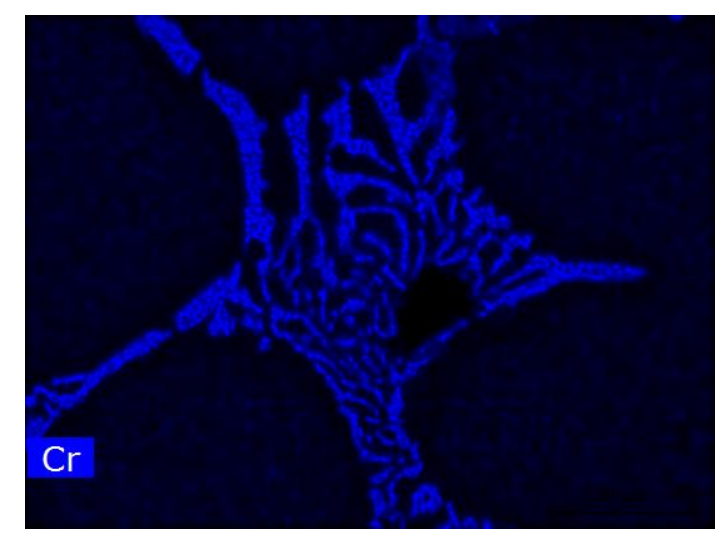

(b)

Figure 4. Cont. 


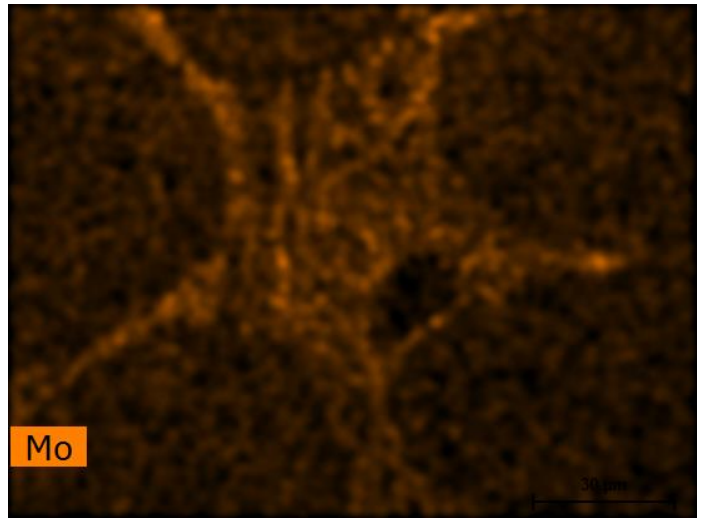

(c)

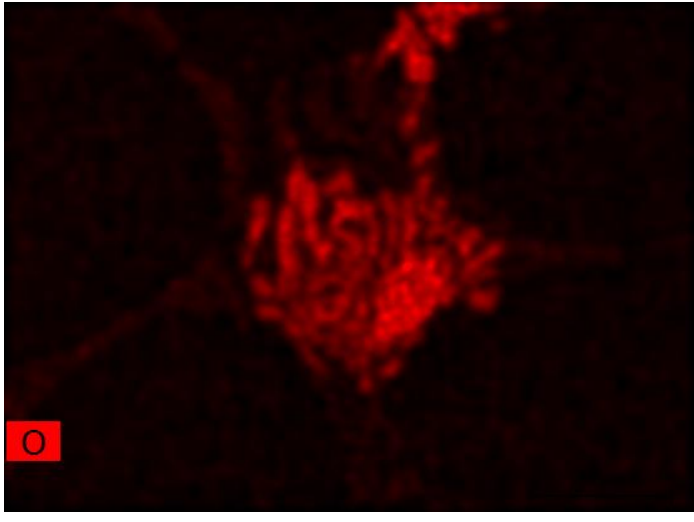

(d)

Figure 4. Oxidized inter eutectic matrix area after 2500 cycles at $700{ }^{\circ} \mathrm{C}$ : (a) BSE micrograph; and elemental distributions of (b) $\mathrm{Cr}$, (c) Mo and (d) O.

\subsubsection{Oxidation Behavior of Cracked Eutectic Carbides at and Close to the Surface}

The elastic thermal stresses on the cooled surface were calculated to be $833 \mathrm{MPa}$ at $500{ }^{\circ} \mathrm{C}$, $1010 \mathrm{MPa}$ at $600^{\circ} \mathrm{C}$ and $1180 \mathrm{MPa}$ at $700^{\circ} \mathrm{C}$. Primary and eutectic carbides located on the cooled surface decompose during thermal fatigue and initially show transverse cracks, as shown in Figure 5a and a detailed view at higher magnification in Figure 5b. The crack shown cuts through carbides and matrix and represents a way in which oxygen penetrates eutectic carbides and causes accelerated oxidation.

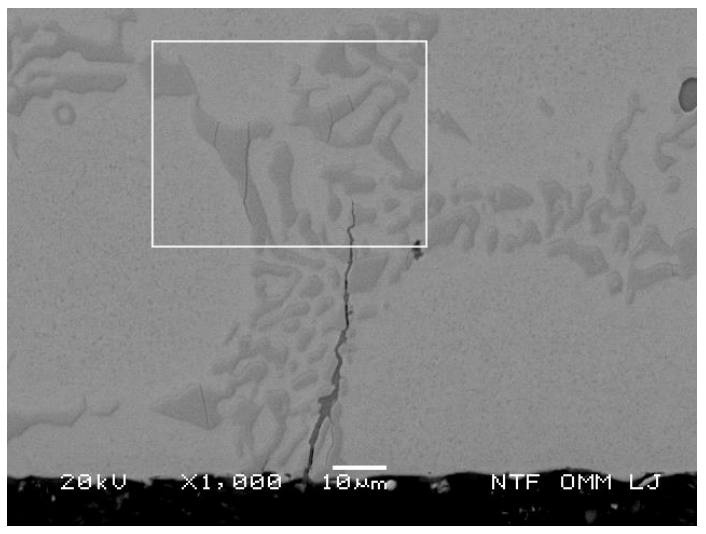

(a)

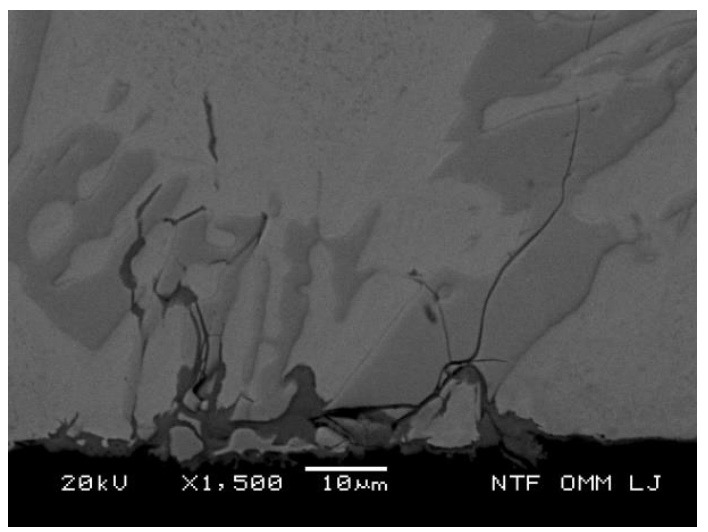

(c)

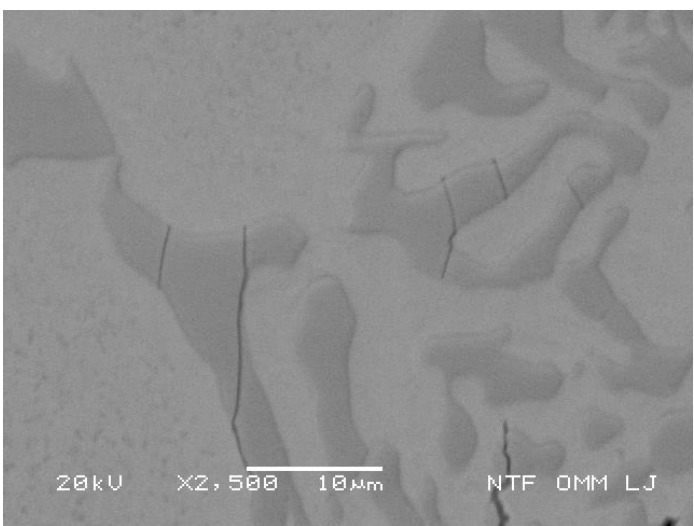

(b)

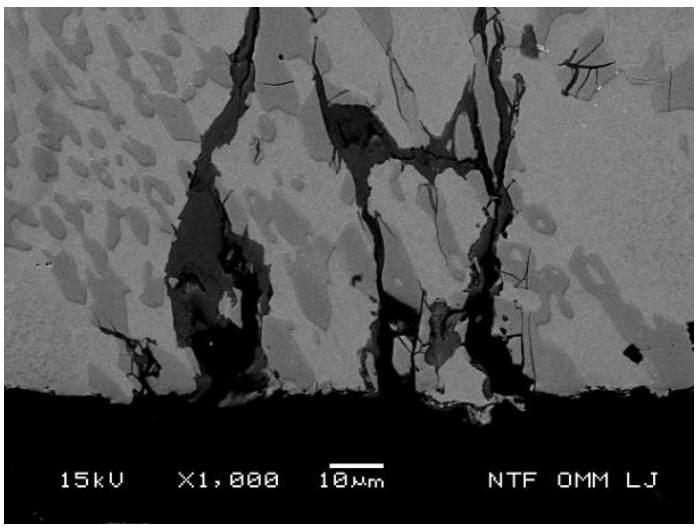

(d)

Figure 5. Cont. 


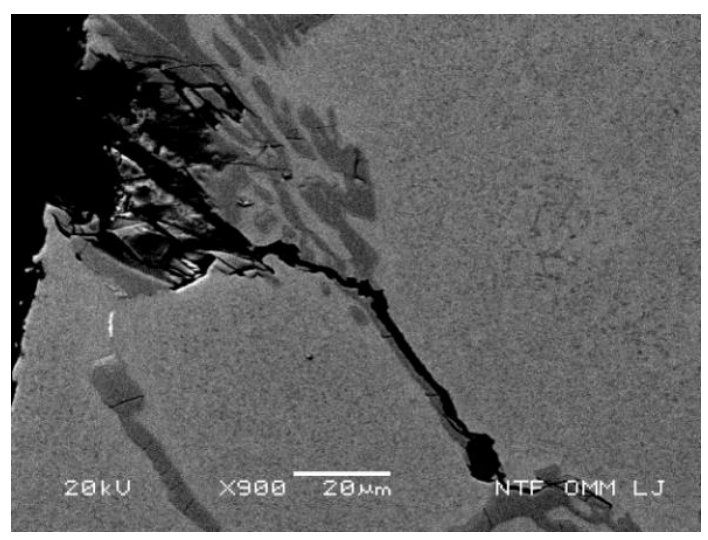

(e)

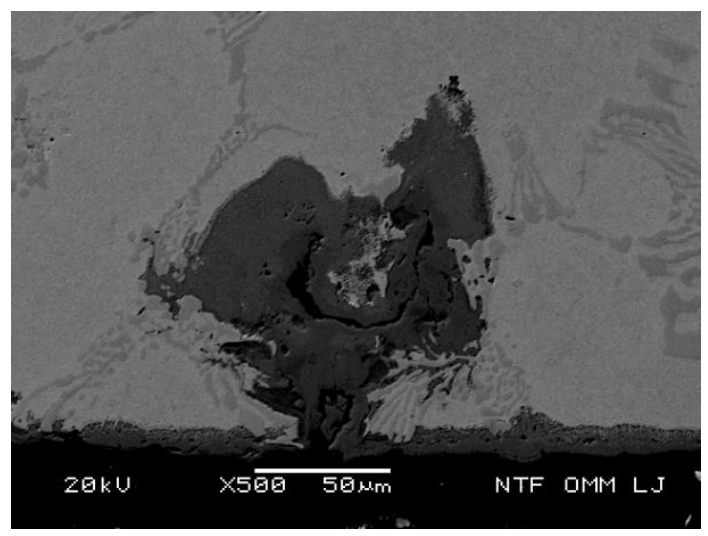

(g)

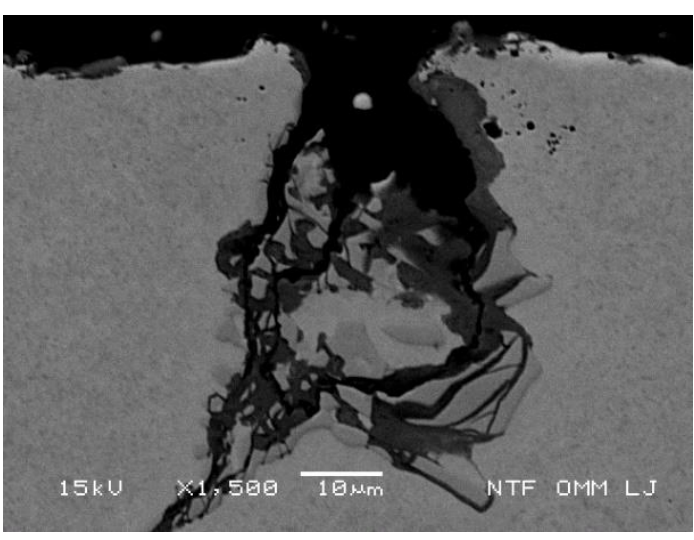

$(\mathbf{f})$

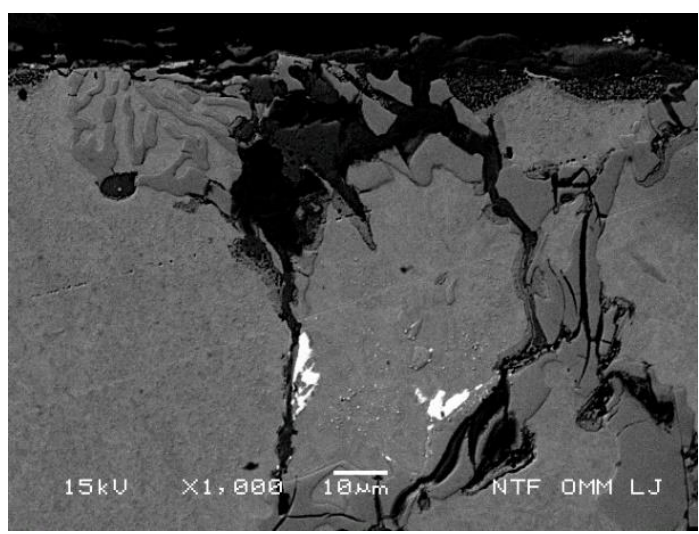

(h)

Figure 5. Oxidation behavior at the cooled surface and cracked eutectic carbides: (a) initial eutectic cracking after 1000 cycles at $500{ }^{\circ} \mathrm{C}$, and (b) higher magnification of the window in subfigure a. Initial oxidation around the cracked eutectic carbide at $600^{\circ} \mathrm{C}$ : (c) after 1000 cycles and (d) after 2500 cycles. Observed oxidation around the eutectic carbides after 2500 cycles: (e) at $500{ }^{\circ} \mathrm{C}$, (f) at $600{ }^{\circ} \mathrm{C}$ and $(\mathbf{g}$,h) at $700{ }^{\circ} \mathrm{C}$ with severely oxidized areas.

Figure $5 c, d$ shows the oxidation taking place on a cracked carbide, the crack being connected to the cooled surface and the oxidation being visible not only in the carbide but also in the matrix. The width of the oxidized region is wider in the matrix compared to the carbide, indicating an increased oxidation rate in the matrix. It should be stressed that larger carbides in eutectic clusters tend to crack (cf. Figure $5 \mathrm{c}$ and [5]), which leads to the formation of new free surfaces and consequently to accelerated oxidation, as shown in Figure 5d. Figure 5e-h shows typical micrographs of oxidized eutectic carbides after thermal cycling at temperatures of 500, 600 and $700{ }^{\circ} \mathrm{C}$ for 2500 cycles each. Not only the less pronounced carbide cracking, but the oxidized area too, is smaller at a lower maximum temperature of the thermal cycle, as shown in Figure 5e for the test performed at a temperature of $500{ }^{\circ} \mathrm{C}$. The comparison with the results obtained at $600{ }^{\circ} \mathrm{C}$ shows a more pronounced carbide cracking and a larger oxidized surface (matrix and carbides), which indicates an increased oxidation rate at higher temperatures (cf. Figure $5 \mathrm{f}$ for $600^{\circ} \mathrm{C}$ ).

The micrograph of the sample tested at $700{ }^{\circ} \mathrm{C}$ showed an even larger oxidized area of matrix and carbide (cf. Figure 5g,h). However, since the area of interest is completely oxidized, cracks that represent paths for oxygen ingress are not easy to detect. As in reference [6], the initial crack propagation is mainly associated with crack growth within carbides. Furthermore, the initial fine crack in thick carbide in Figure $5 \mathrm{c}$ indicates that crack growth in the early stages is not combined with oxidation. In the later stages of crack growth, however, oxidation plays an important role in the crack 
formation pathway. The occurrence of carbide cracks on the cooled surface without any oxidation can be attributed to high thermal stresses at high test temperatures. The internal degradation (oxidation) of the cooled surface layer is associated with eutectic carbides, which are located up to a distance of approximately $400 \mu \mathrm{m}$ below the cooled surface. The first stage of cracking and oxidation of eutectic carbide located below the cooled surface is shown in Figure 6a. Observation of the sample, thermally cycled for 500 cycles at the maximum temperature of $600{ }^{\circ} \mathrm{C}$, showed that the cracks extend to the cooled surface, allowing oxygen to enter. The next stage of surface degradation by eutectic carbide below the cooled surface is shown in Figure 6b. Shown are oxidation and cracks in the eutectic carbides and matrix in the sample tested at $600{ }^{\circ} \mathrm{C}$ for 2500 thermal cycles. The oxidation progress of cracked eutectic carbide, where the oxidized region increases a few times in area compared to the initial region, is shown in Figure $6 \mathrm{c}$ and detailed view in Figure $6 \mathrm{~d}$. A similar observation of the oxidation of eutectic carbide and the connection of cracks to the cooled surface is shown in Figure 6e, and a detailed view is shown in Figure $6 \mathrm{f}$ (obtained for the sample tested at a temperature of $700{ }^{\circ} \mathrm{C}$ for 2500 cycles). At this point, note the importance of the axial oxidation direction, which is essential for the connection of radial cracks. Crack formation in the axial direction is a consequence of radial stress (cf. Figure 1b). In the detailed view (cf. Figure $6 \mathrm{f}$ ) the progress of the highlighted oxidized area is visible, in which the crack path follows the outer part of the eutectic carbide cluster with thicker carbides compared to the inner lamellar carbides. In Figure 6e, several oxidized eutectic regions are present and a small oxidized crack is visible. In this case, the degradation process continues with oxidation and crack propagation in all three independent eutectic regions. In time, these three areas will be connected to each other in a closed area that is at risk of spalling. The formation of the oxidation pathway in combination with the preceding cracking of thick eutectic carbides accelerates oxidation and coalescence with cracks in the primary carbides. The coalescence of the cracks then leads to an area surrounded by cracks, which tends to increased oxidation and premature spalling. 


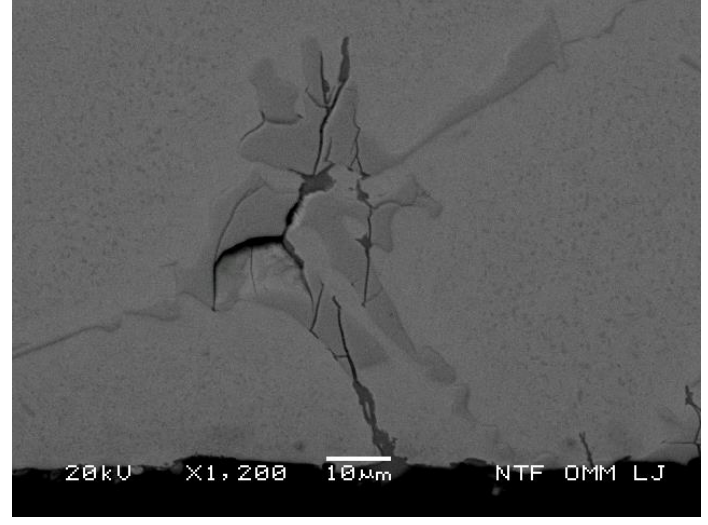

(a)

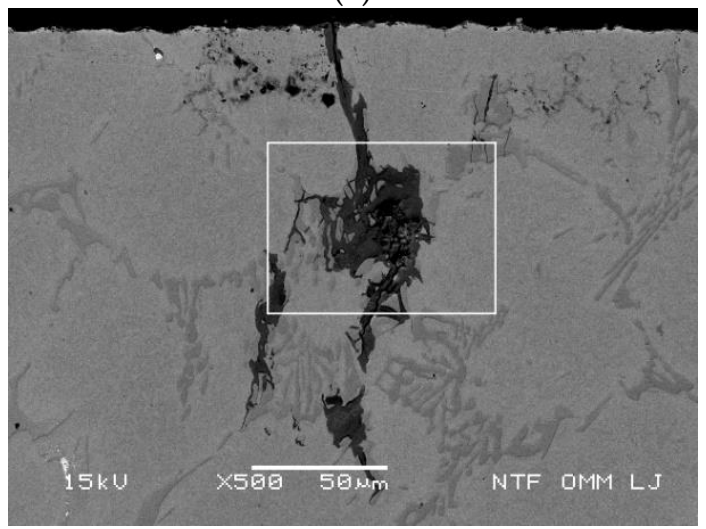

(c)

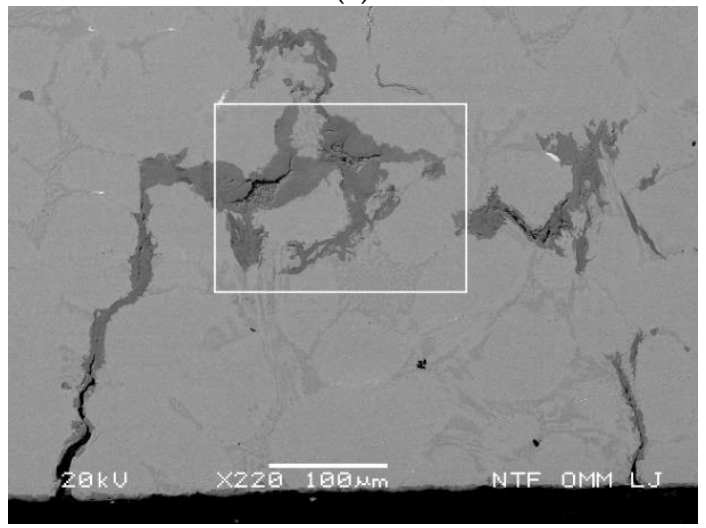

(e)

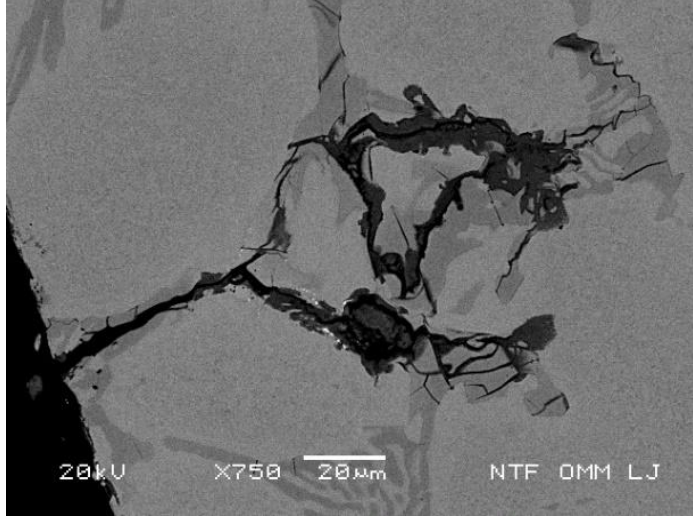

(b)

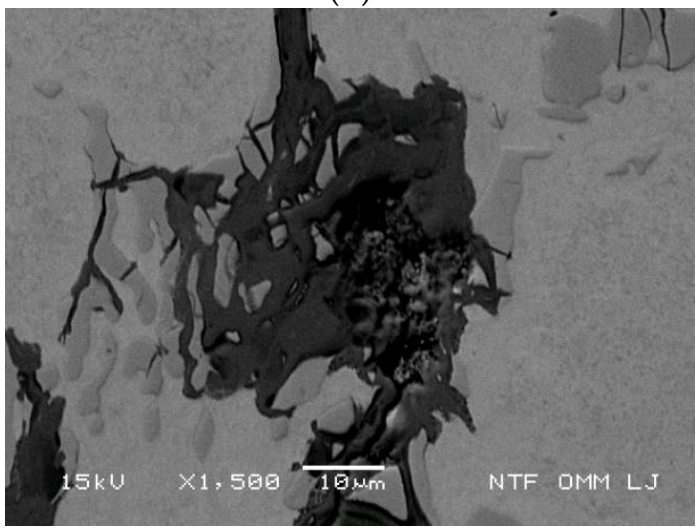

(d)

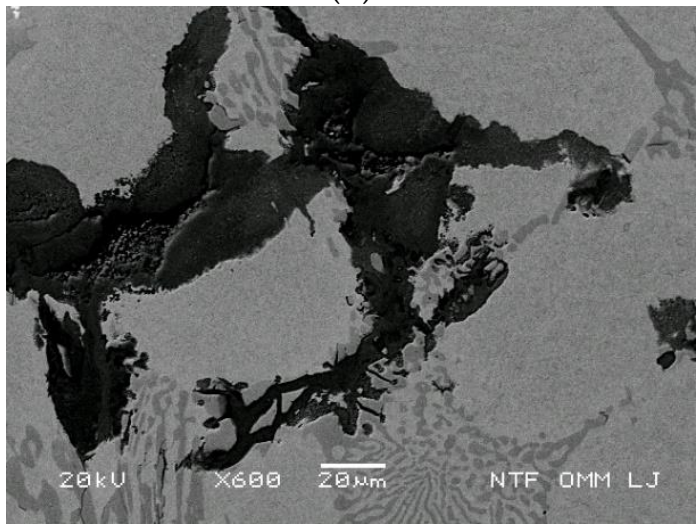

(f)

Figure 6. Oxidation of the cracked eutectic carbides below the cooled surface with the crack canal to the cooled surface: (a) cracking and initial oxidation of the subsurface eutectic after 500 cycles at 600 ${ }^{\circ} \mathrm{C}$, (b) after 1000 cycles at $600{ }^{\circ} \mathrm{C}$, (c) after 2500 cycles at $600{ }^{\circ} \mathrm{C}$ with marked area for the detail, (d) micrograph of the detail of oxidized eutectic cluster, (e) oxidation area expansion in the axial direction after 2500 cycles at $700{ }^{\circ} \mathrm{C}$ and, (f) detailed view of the area marked in the subfigure e.

\subsubsection{Oxidation of the Matrix at the Cooled Surface and Oxidation Growth Front}

Increased temperature increases oxidation not only of the cracked matrix (in the eutectic) but also of the matrix at the cooled surface, as shown in Figure $7 \mathrm{a}$ after 2500 thermal cycles at the maximum temperature of $700{ }^{\circ} \mathrm{C}$. The thickness of the oxide layer varies and was measured in the range 5-8 $\mu \mathrm{m}$ at the maximum temperature of $700{ }^{\circ} \mathrm{C}$. Compared to the measured oxide layer thickness of $1-2 \mu \mathrm{m}$ at the maximum temperature of $600{ }^{\circ} \mathrm{C}$, the increased temperature leads to significant oxide growth. Observation of the sample at the lowest maximum temperature $\left(500^{\circ} \mathrm{C}\right)$ leads to a negligible oxide layer. The observation of damage on several samples tested at different temperatures led to the conclusion 
that the oxidation process is stress related. The process of matrix oxidation from the cooled surface develops perpendicularly to the axial thermal stress component. Figure $7 \mathrm{~b}$ shows the penetration of oxygen by the formation of a narrow oxide wedge in the matrix, tested at $600{ }^{\circ} \mathrm{C}$ for 1000 thermal cycles. The angle of inclination of the oxide front is almost perpendicular to the cooled surface and thus almost perpendicular to the thermal stress acting on it. The same applies to the micrograph in Figure $7 c$, where three oxide wedges are again almost perpendicular to the cooled surface.

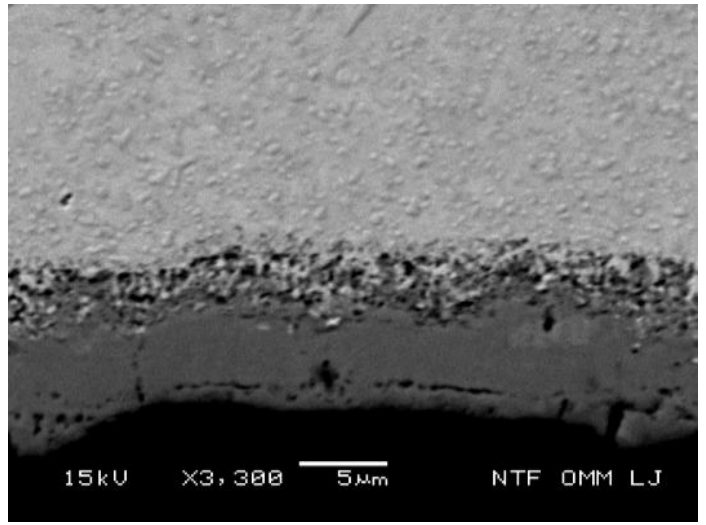

(a)

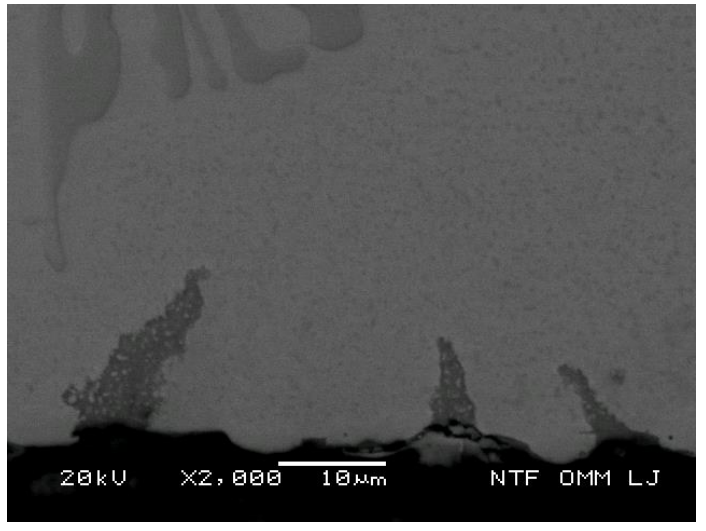

(c)

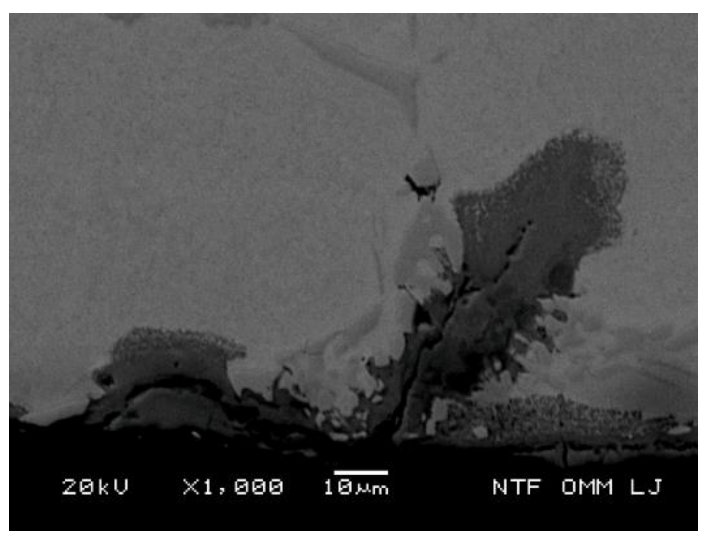

(e)

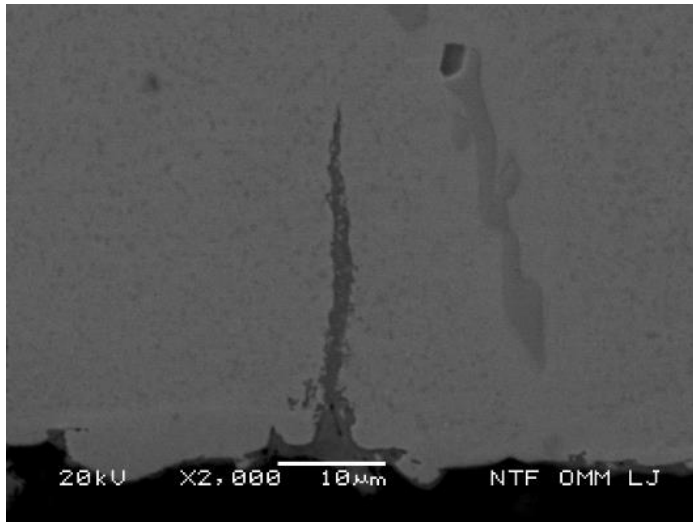

(b)

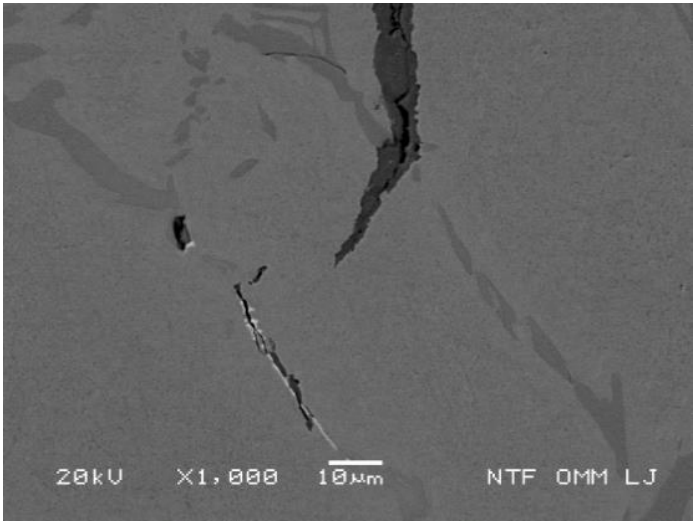

(d)

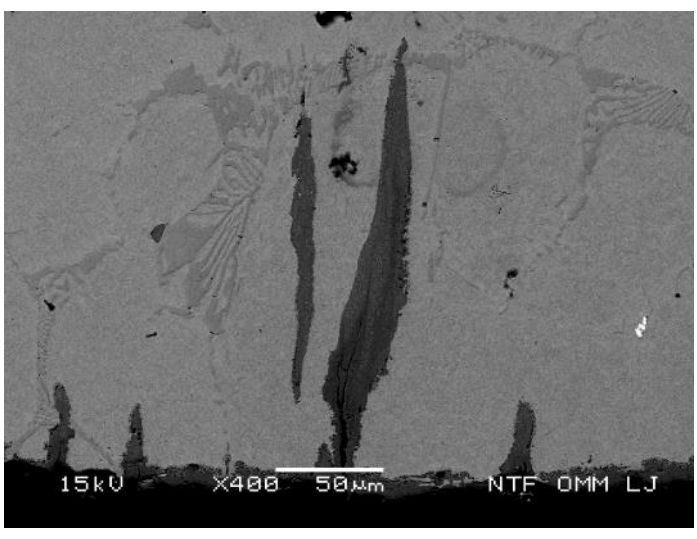

(f)

Figure 7. Oxidation in the matrix and cooled surface: (a) oxidation of surface after 2500 cycles at $700{ }^{\circ} \mathrm{C}$, $(\mathbf{b}, \mathbf{c})$ oxidation tongues after 1000 cycles at $600^{\circ} \mathrm{C}$, (d) oxidation direction deviation toward internal crack tip, (e) increased oxide band originating on the small cracked carbide after 1000 cycles at $700{ }^{\circ} \mathrm{C}$ and (f) larger oxide tongue in the matrix originating from the surface after 2500 cycled at $700{ }^{\circ} \mathrm{C}$. 
A slightly opposite inclination of the outer oxide wedges can be attributed to stresses caused by inner cracks that act outside the section shown. The stress dependent direction of oxide growth due to internal cracks is shown in Figure 7d. The visible deflection of the growth direction of the oxide front is caused by stresses at the tip of the inner crack, which occur before the main crack. Therefore, the direction of matrix oxidation is stress related and follows the maximum effective stress. The oxidation front begins to grow perpendicularly to the cooled surface and the growth direction deflection can later be influenced by stresses resulting from the internal cracks. The width of the oxidation front is relative and depends on the test conditions, as shown in Figure 7e (right) for the case of a high test temperature of $700{ }^{\circ} \mathrm{C}$ and 1000 thermal cycles. The inclination of the oxide front direction can be attributed to the inclination angle of the nucleated small crack in the eutectic carbide, and the stress field acting on the crack tip. The oxidation front shown as a wide band is present on the left micrograph. In addition, several short and a single long oxide wedges in Figure $7 \mathrm{f}$ are again perpendicular to the cooled surface. Wider oxide wedges are attributed to the higher thermal stress, as they are located near the cooled surface, and to the higher test temperature $\left(700^{\circ} \mathrm{C}\right)$. A common feature of the oxide wedges observed in Figure $7 \mathrm{~b}, \mathrm{c}, \mathrm{e}, \mathrm{f}$ is that their inclination is not related to the carbides present. From this it can be concluded that the growth direction of the oxide front is stress-dependent and that oxidation progresses from the stress field of the greatest thermal stress to stress fields at the inner crack tips.

\subsubsection{Oxidation Behavior and Crack Growth Direction at High Thermal Stresses}

In general, crack growth at high thermal stresses (above approx. $900 \mathrm{MPa}$ ) can be divided into three different stages with regard to the contribution of carbide oxidation in relation to thermal stresses (cracking, crushing). In each of the three phases the contribution by oxidation is different. In stage (i), oxidation plays no significant role in crack growth, which occurs due to carbide cracking and crushing as a result of high thermal stresses (cf. Figure 5c, Figure 6a). This is especially true for the thicker carbides, which are precipitated below the surface at depths where the thermal stress is still high. Characteristic for the second stage (ii) is the lower thermal stress compared to stage (i). In this stage, crack growth is caused by carbide cracking (crushing) and by crack tip and canal oxidation.

The consequence of the oxidized material around the crack canal is an additional strain at the crack tip due to the increased volume of the oxides. In addition, the strain field around the crack canal and the crack tip oxygen diffusion to the crack tip and at the same time reduces the mechanical properties of the material around the crack tip. This results in an increased crack growth rate. The crack growth in the first and second phase mainly follows the carbide pathway. In contrast, the contribution of oxidation is relatively greater for crack growth in stage (iii) compared to the contribution of oxidation in stages (ii) and (i). The orientation of crack growth in the stage (iii) is mostly perpendicular to the cooled surface and follows the path in the matrix. However, when carbides act as obstacles at the crack tip, deviations of the crack growth direction have been observed. This was attributed to the stress field around the crack tip of the nearby internal cracks. In addition, a straight line path of crack growth in the matrix was observed when the thermal stresses acting are relatively low, i.e., thermal stresses do not cause carbide cracking in the direction perpendicular to the cooled surface. Crack nucleation and growth occurs next to the carbides also when the carbide orientation is at a low angle of inclination to the cooled surface (see Figure $8 a, b$ ). In the first stage of crack growth as a result of high thermal tensile stresses, the crushing and cracking of carbides was observed. This stress release mechanism consequently causes crack growth following carbide path, regardless of the orientation of the carbides. A higher magnification of the marked area in Figure 8a is shown in Figure 8c, where crack nucleation and carbide crushing is shown. Due to the sufficient ductility of the matrix, the cracking of carbides is caused by the strain due to thermal stress, whereby the toughness of the carbides is significantly reduced compared to the toughness of the matrix. As a result, crack growth in this mode begins independently of carbide orientation by following the carbide path. Figure $8 \mathrm{~d}$,e show the rapid oxidation of crack canals in cracks caused by high thermal stresses. From this it can be concluded that crack growth in the first oxidation stage follows the initial crushing and crack formation of the carbides 
(cf. Figure $8 \mathrm{f}$ ). Overall it can be said that in the case of high thermal stresses, oxidation has reduced role in crack nucleation and initial growth process.

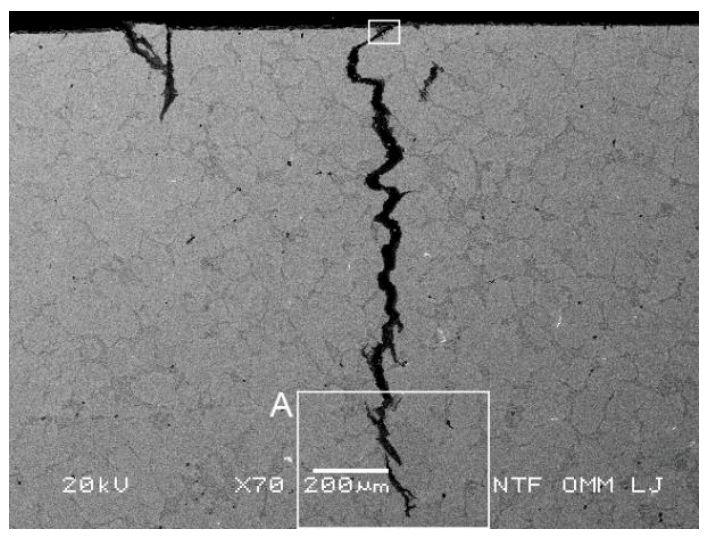

(a)

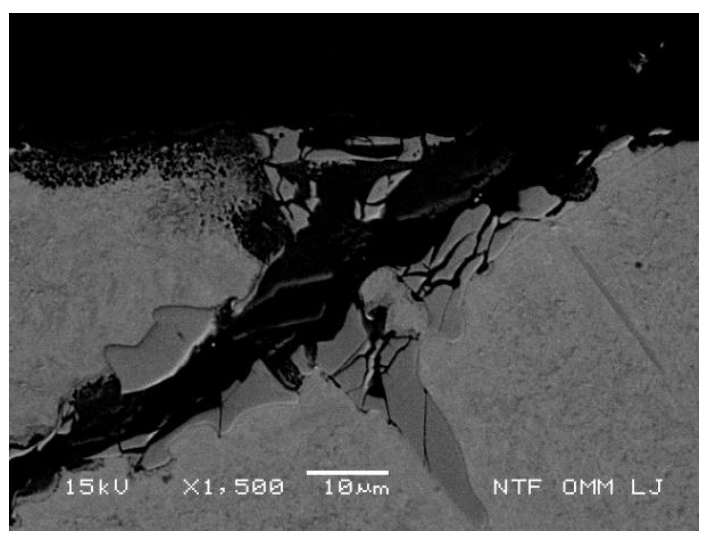

(c)

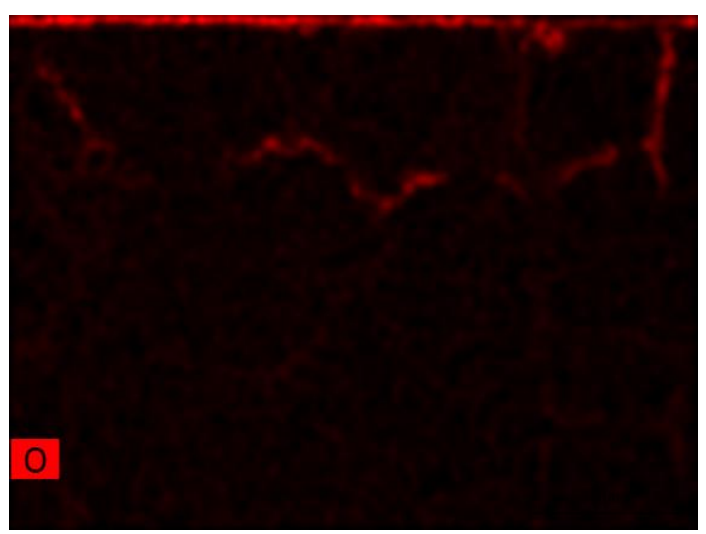

(e)

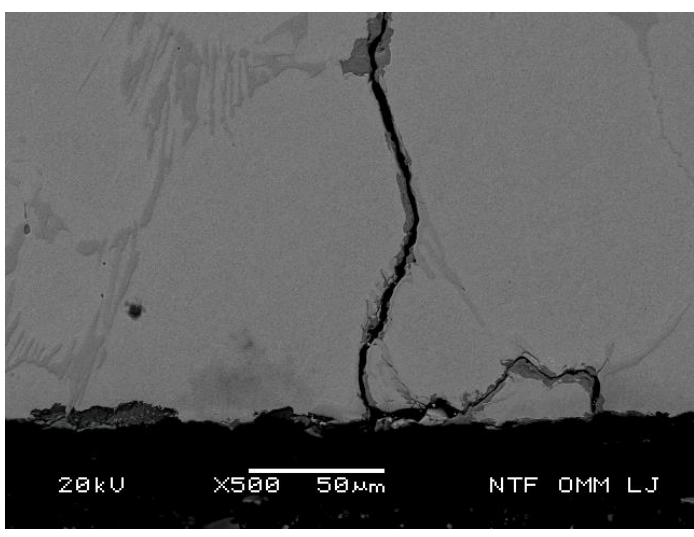

(b)

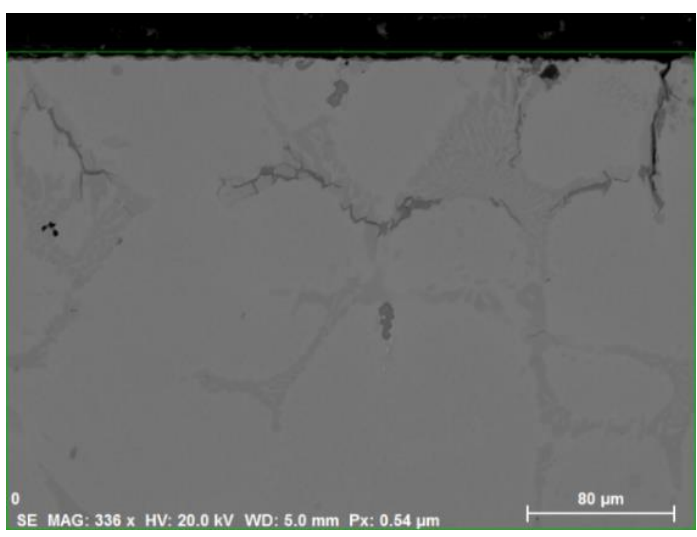

(d)

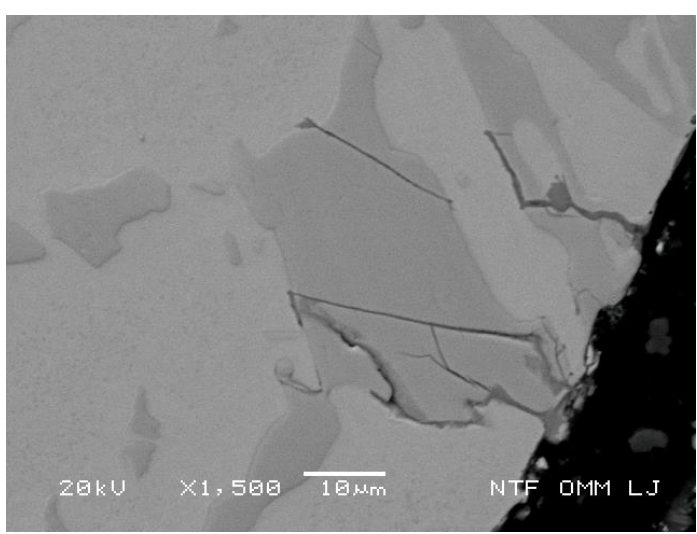

(f)

Figure 8. Influence of high effective thermal stress on the oxidation behavior and crack growth: (a) cracking and crushing of carbides, crack growth using the carbide pathway and oxidation after 2500 cycles at $700{ }^{\circ} \mathrm{C}$-marked areas of detail A (Figure 11a) and subfigure c; (b) crack pathway and oxidation after 1000 cycles at $600{ }^{\circ} \mathrm{C}$; (c) crushing and oxidation of thick carbides; (d) occurrence of initial internal cracks, cracking and oxidation of cracked and crushed carbides under the cooled surface after 2500 cycles at $600{ }^{\circ} \mathrm{C}$; (e) distribution of $\mathrm{O}$ in the subfigure d; and (f) initial stage of enlarged carbide cracking and crushing at the cooled surface after 1000 cycles at $500{ }^{\circ} \mathrm{C}$. 
Figure 9a shows an intensive oxidation of the eutectic region. A large oxidized area the beginning of the crack canal is visible, followed by an oxidized area of eutectic carbides. Surface bulges or elevations on the surface where the crack canal begins are also observed. In the second case, shown in Figure 9b, large oxidized eutectic regions exhibit extensive carbide cracks due to increased stresses near the crack tip. This is exhibited shown by crack branching and the occurrence of internal cracks in carbides. Therefore, oxidation of the eutectic region accelerates crack growth due to increased internal cracks formation around the crack tip as a result of increased stress on the oxidized regions.

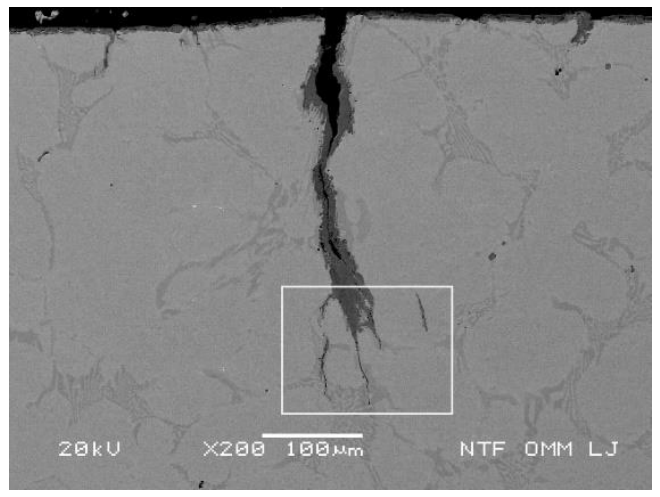

(a)

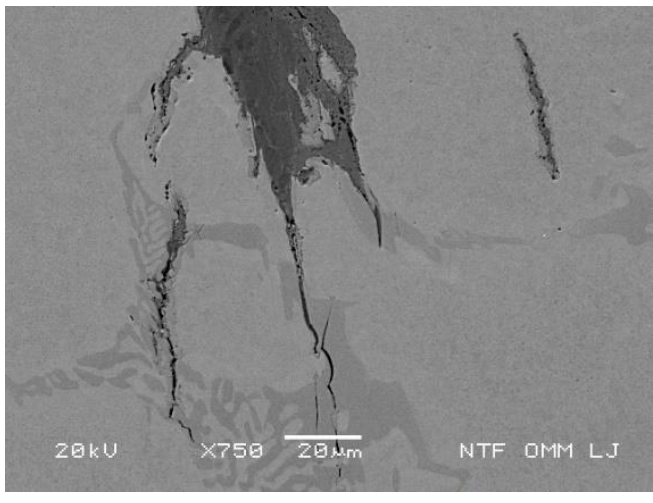

(b)

Figure 9. Deformation due to the oxide volume change and crack oxidation next to the eutectic carbide after 2500 cycles at $700{ }^{\circ} \mathrm{C}$ : (a) oxidation of the secondary crack and surface material deformation with marked area of the detail and, (b) detailed view of increased oxidation of the crack tip.

\subsubsection{Oxidation Behavior and Crack Growth Direction during Medium Thermal Stress}

According to our estimation, the medium thermal stresses are in the range between 700 and $900 \mathrm{MPa}$. FEM simulations show that this is at a depth of about $10 \mu \mathrm{m}$ at a test temperature of $500{ }^{\circ} \mathrm{C}$. At 600 and $700{ }^{\circ} \mathrm{C}$, medium stresses at depths between 6 and $17 \mu \mathrm{m}$ and 14 and $25 \mu \mathrm{m}$ are expected, respectively.

An increased crack length leads to a decrease in thermal stress and consequently to changes in crack propagation conditions. Changed crack propagation conditions are referred to here as the second stage of crack development. In this phase, a reduced thermal stress with the number of cycles is responsible for decreased crushing of the carbides. However, the thermal stresses at the crack tip are still sufficiently high, leading to the occurrence of an internal cracks near the crack tip. This leads to oxidation of the crack tip and the internal crack canals' oxidation (cf. Figure 9). As a result of the latter, the strength of the surrounding material is reduced, which leads to accelerated crack growth. Characteristic of this stage is that the crack growth still mainly follows the carbide/matrix boundaries (see Figure 10a-d). If the crack follows the carbide/matrix boundary, it is called a carbide pathway. The oxidation of the crack tip and the crack canal in front of the crack tip contributes to the subsequent crack growth with regard to thermal stress. Figure 10a shows the entire crack with a marked area where $\mathrm{Cr}$ and $\mathrm{O}$ were mapped. The distribution of $\mathrm{Cr}$ is shown in Figure 10b, while the elemental map of oxygen is shown in Figure 10c. Figure 10d is a typical micrograph taken in the depth of expected medium thermal stresses. The crack follows the carbide pathway and there are slight carbide cracks. Crack nucleation and initial growth follow the carbide pathway regardless of the orientation of the primary or eutectic carbides. At this stage, a very versatile crack growth direction is characteristic, which sometimes leads to a curved crack shape. 


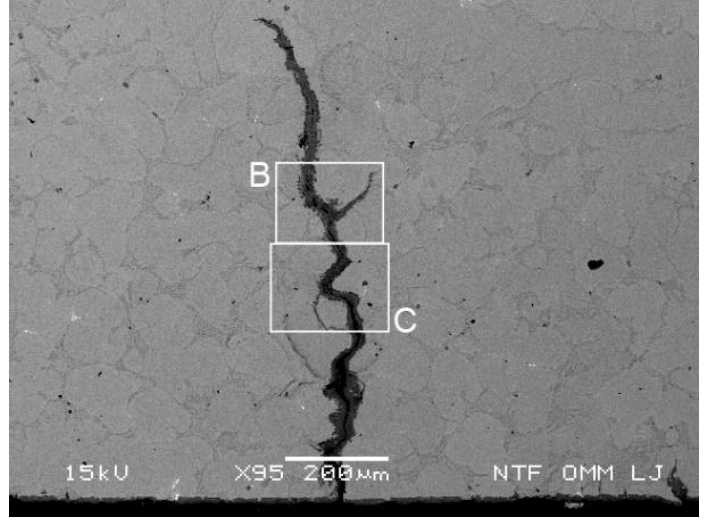

(a)

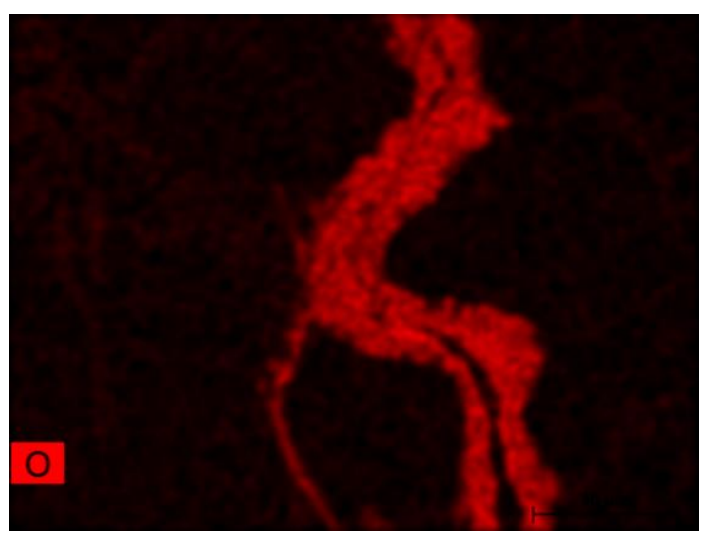

(c)

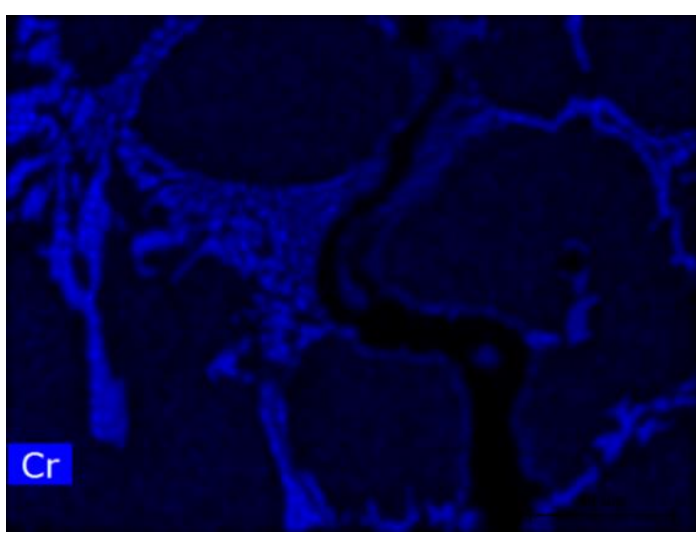

(b)

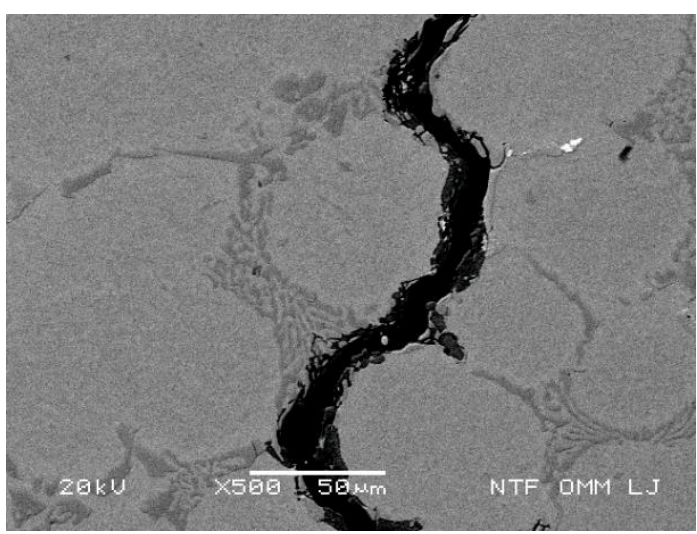

(d)

Figure 10. Influence of the medium effective thermal stress on the oxidation behavior: (a) micrograph of the oxidized crack canal-marked areas B (Figure 14c) and C (EDX elemental maps in the subfigures $\mathrm{b}$ and c); (b) distribution of $\mathrm{Cr}$; (c) distribution of $\mathrm{O}$; and (d) typical appearance of the crack and oxide following the carbide pathway at the medium effective thermal stress after 2500 cycles at $700{ }^{\circ} \mathrm{C}$.

\subsubsection{Oxidation Behavior and Crack Growth Direction at Lower Thermal Stress}

The third stage of crack growth was associated with an additional decrease in thermal stress. The cracking and crushing of carbides decreases as a result of the decrease in thermal stress. At this stage, oxidation behavior shows increased significance. A slight contribution of crack formation and crushing of carbides still contributes to crack growth-to a lesser extent, however, than in the first and second stage. The effective thermal stress acting in this phase is estimated to be below $700 \mathrm{MPa}$. Due to small thermal stresses, primary and secondary cracks deeper in the material were observed at depths of more than $1300 \mu \mathrm{m}$.

According to our estimation, the medium thermal stresses are in the range between 700 and $900 \mathrm{MPa}$. FEM simulations show that this is at a depth of about $10 \mu \mathrm{m}$ at a test temperature of $500{ }^{\circ} \mathrm{C}$. At 600 and $700{ }^{\circ} \mathrm{C}$, medium stresses at depths between 6 and $17 \mu \mathrm{m}$ and 14 and $25 \mu \mathrm{m}$ are expected, respectively.

\section{Oxidation Behavior of the Primary Crack Propagating Perpendicular to the Cooled Surface}

At the test temperature of $700{ }^{\circ} \mathrm{C}$, a thermal stress of about $410 \mathrm{MPa}$ was determined at a depth of $1300 \mu \mathrm{m}$. Similar stresses are achieved at a test temperature of $600{ }^{\circ} \mathrm{C}$ at a depth of $1420 \mu \mathrm{m}$ and at a depth of $1600 \mu \mathrm{m}$ at $500{ }^{\circ} \mathrm{C}$. Characteristic of crack growth under these conditions is that the crack propagation through the matrix is in a direction perpendicular to the cooled surface, even if the carbides are not oriented perpendicularly to the cooled surface. If the oxidation process is strong, it helps crack 
propagation through the matrix. In cases where no oxidation is present, the crack propagation rate decreases as the crack tip enters the matrix [6].

The strain field originating from the crack tip can still cause internal cracks, as shown in Figure 9. Internal cracks usually appear near the crack tip in the eutectic carbide region. The growth direction of the cracks through the area of the carbides with merging internal cracks does not deviate significantly from the perpendicular direction to the cooled surface. The direction of crack growth does not change the inclination (see detail A in Figures 8a and 11a). Furthermore, the straightness of the crack increases in the direction of growth. In general, crack propagation follows the carbide pathway if its orientation with respect to the direction of the thermal stress does not deviate significantly from the perpendicular orientation to the cooled surface. The straight-line appearance of cracks is an important feature in the third stage of crack growth. Figure 11a shows that if the carbides are distributed in a direction perpendicular to the cooled surface, the internal cracks formed lead to the formation of a global crack. In contrast, the crack propagates through the matrix when the carbides are not oriented near the perpendicular direction to the cooled surface. The favorable oxidation direction is perpendicular to the maximum effective thermal stresses, as shown in Figure $11 \mathrm{~b}$ (detailed view of the crack tip in the marked area), for the radial direction after 1000 thermal cycles at a test temperature of 600 . Figure $11 \mathrm{c}$ shows two different cases (see marked areas on the left and right side) for the final stages of crack growth at depths of more than $1000 \mu \mathrm{m}$. It is important to note that the conditions shown apply to low thermal stress, where the importance of oxidation increases. The section in the left hand rectangle in Figure 11c shows the formation of an internal crack in front of the crack tip of the primary crack. In the next stage of crack growth, an internal crack formed in the carbide fuses before the crack tip and the crack propagates through the matrix. It can also be seen that the inner crack direction does not deviate from the vertical direction.

On the other hand, the crack shown in detail in the right rectangle in Figure 11c does not cause the formation of internal cracks in carbides due to the low thermal and crack tip stress. In this case the influence of oxidation on crack growth is increased compared to the first and second stage. It can be noted that in the case without internal carbide cracks, the crack propagation is in the oxidation favorable position in the matrix ( $\mathrm{Cr}$ depleted areas adjacent to carbides). In contrast, in the case of high thermal stresses, internal carbide cracks precede crack growth and the direction of crack growth would follow the carbide path. Furthermore, as shown in Figure 11d in the area marked in detail, crack growth due to oxidation can occur and follow the carbide/matrix interface if no carbides are present near the crack tip and the magnitude of the applied thermal stress is sufficient. In cases wherein oxidation plays a decisive role, the crack growth direction can follow the carbide/matrix interface perpendicularly to the cooled surface and does not only propagate through the matrix. Figure 11e shows two different types of crack growth observed after 2500 cycles at $700{ }^{\circ} \mathrm{C}$. The first type involves the formation of internal cracks in carbides and grow by oxidation in both directions; i.e., to and from the cooled surface. Characteristic of the second type of oxidation growth is the formation of two oxidation tongues at the carbide/matrix interface. In Figure 11f, oxidation was observed at the carbide/matrix interface after 2500 cycles at $500{ }^{\circ} \mathrm{C}$. The oxidation direction at the tip of the carbide deviates and continues in the direction perpendicular to the cooled surface (i.e., perpendicular to the influence of the axial thermal stress). The occurrence of cracks at the carbide/matrix interface near the oxidation crack tip indicates a reduced adhesion between the mentioned microstructural features. Growth through the matrix in the vertical direction and growth after the carbide/matrix interface are the second and third possibilities respectively. These things happen in cases in which the crack formation of carbides does not occur near the crack tip and the angle of inclination of carbide/matrix is low enough. 


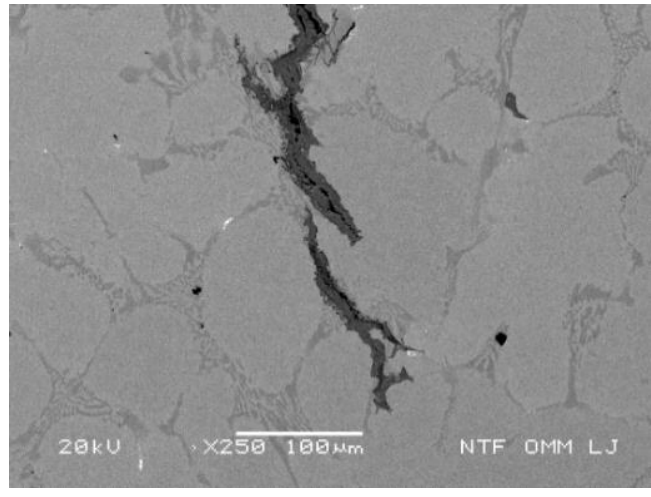

(a)

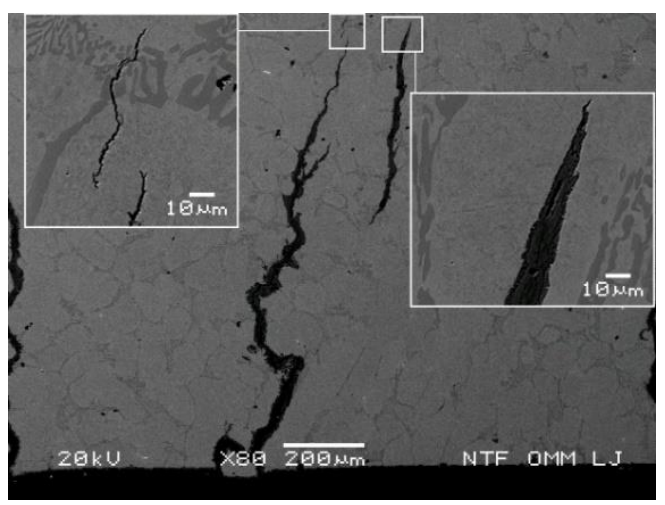

(c)

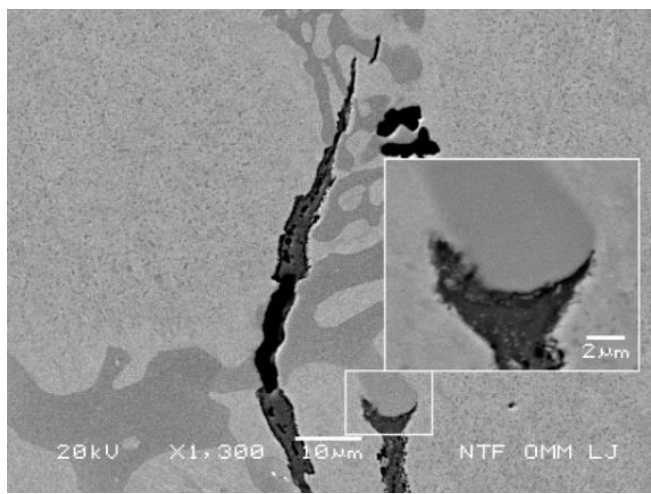

(e)

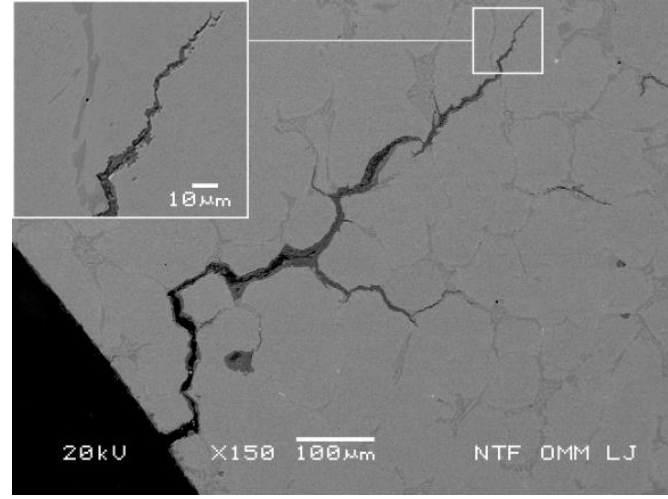

(b)

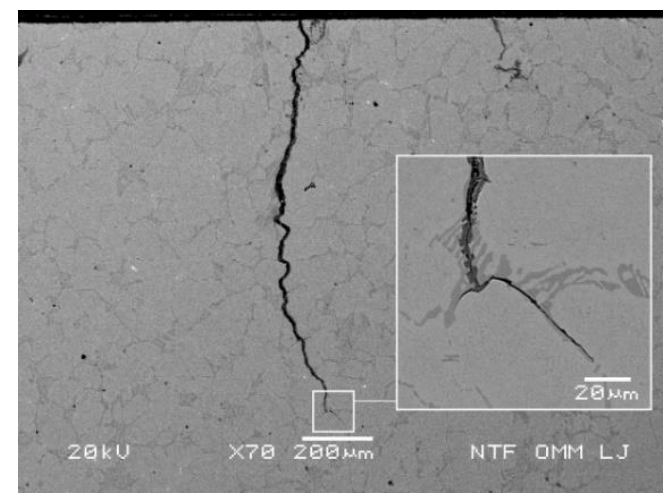

(d)

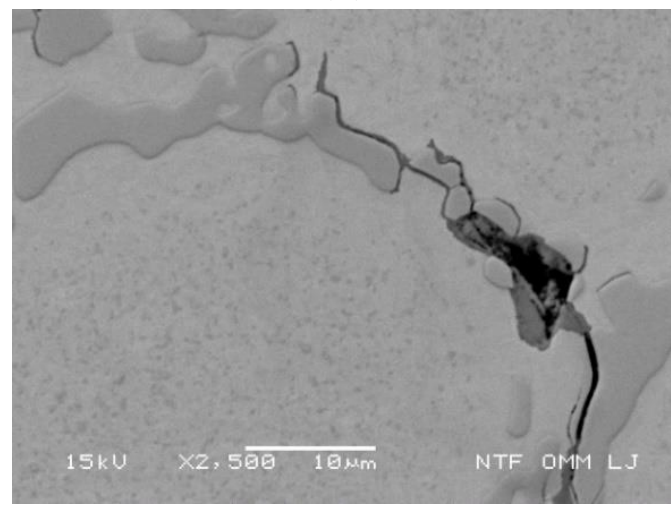

(f)

Figure 11. Influence of low effective thermal stress on oxidation behavior: (a) micrograph of increased straightness at the end of primary crack after 2500 cycles at $700{ }^{\circ} \mathrm{C}$ of the area A in Figure $8 \mathrm{a}$; (b) crack in radial cross section and detailed view of the crack tip after 1000 cycles at $600{ }^{\circ} \mathrm{C}$; (c) crack growth and formation of internal crack in carbide cluster located in the crack growth direction in the left detailed area, and detail on the right is crack growth in the matrix between eutectic carbides without internal crack at carbides; (d) crack canal oxidation and crack growth following the carbide/matrix interface observed after 1000 cycles at $700{ }^{\circ} \mathrm{C}$; (e) formation of the internal crack in carbide before crack tip of the primary crack-(top) oxidation of carbide, and oxide branching at the larger carbide (bottom) after 2500 cycles at $700{ }^{\circ} \mathrm{C} ;(\mathbf{f})$ oxidation of the carbide/matrix interface and oxidation direction deviation to the perpendicular orientation after 2500 cycles at $500{ }^{\circ} \mathrm{C}$.

Oxidation Behavior and Crack Growth Direction in the End Regions of the Secondary Cracks at 500 and $700{ }^{\circ} \mathrm{C}$

It is characteristic of the formation of secondary cracks that their formation occurs at significantly lower thermal stresses compared to primary cracks. However, the formation of primary cracks in their 
final phase is also associated with lower thermal stress. From this it can be deduced that a similar role of oxidation and carbide cracking can be observed in the growth of secondary cracks as in the growth of primary cracks at a depth of more than $1300 \mu \mathrm{m}$. Figure 12a,b shows for the test temperature of $500{ }^{\circ} \mathrm{C}$ (Figure 12a for 1000 cycles and Figure 12b for 2500 cycles) that in the case of lower thermal stresses, cracking follows the carbide/matrix pathway and the influence of oxidation is emphasized. Cracking of carbides along the crack path is negligible and indicates a lower thermal stress and an increased importance of oxidation. From the point of view of material strength, the carbide/matrix interface is not a weak spot and crack growth through this area is strongly associated with oxidation. Moreover, in the approximately $4 \mu \mathrm{m}$ wide band along the carbides, the $\mathrm{Cr}$ content is reduced and was measured with EDX in the range of $4-5 \mathrm{wt}$. \%. In comparison, the $\mathrm{Cr}$ content in the matrix is in the range of 6-8.5 wt. \%. After 2500 cycles (cf. Figure 12b) it can clearly be observed that the crack formation in carbides is low. However, the crack formation in carbides is slightly increased compared to the observation after 1000 cycles (see Figure 12a). From the observations made it can be said that both crack tip oxidation and internal oxidation of the crack canal are the driving forces of crack growth.

As expected, the observed oxidation surface is larger at the test temperature of $700{ }^{\circ} \mathrm{C}$ than at the test temperature of $500{ }^{\circ} \mathrm{C}$. Nucleation sites for cracks are carbides of the carbide/matrix interface. For a case in which the orientation of the carbides deviates significantly from the vertical direction, the crack follows the oxidation path. This means that the crack growth is oriented in the direction of the maximum thermal stress (see Figure 12c for the condition after 1000 cycles). Figure $12 \mathrm{~d}$ shows that after 2500 cycles crack nucleation occurred on eutectic carbides. At a depth of about $90 \mu \mathrm{m}$, the crack growth mode starts through the matrix and runs perpendicularly to the cooled surface. This confirms that the crack path does not always follow the carbide path or the carbide/matrix interface path.

In the case wherein the secondary crack follows the carbide path, the final phase is similar to the final phase of longer cracks (see Figure 11), since in both cases the thermal stresses are low. Reduced internal micro-crack formation occurs when the influence of thermal stress is low. In case of a small inclination angle of the carbides, this leads to changes in the crack propagation path. The crack leaves the carbide path and takes up the matrix path; i.e., the direction of growth becomes, in steps, perpendicular to the cooled surface (see Figure 12e). Similar things can be seen in Figure 12f, but in the latter case the formation of two branches in the matrix in the favorable oxidation direction is visible. The branching of the crack is perpendicular to the cooled surface, where higher thermal stresses occur. 


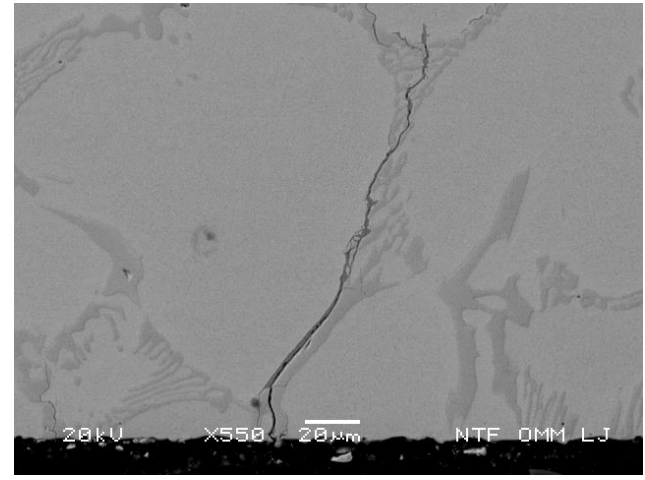

(a)

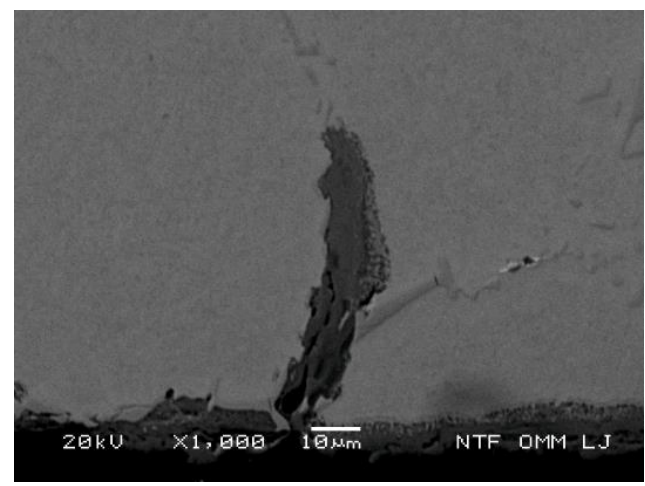

(c)

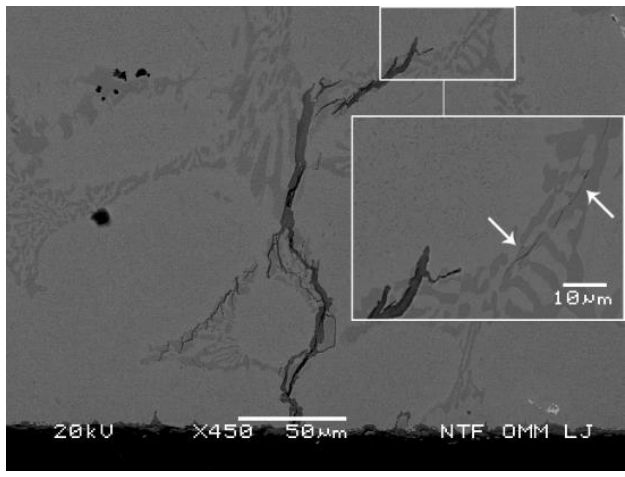

(e)

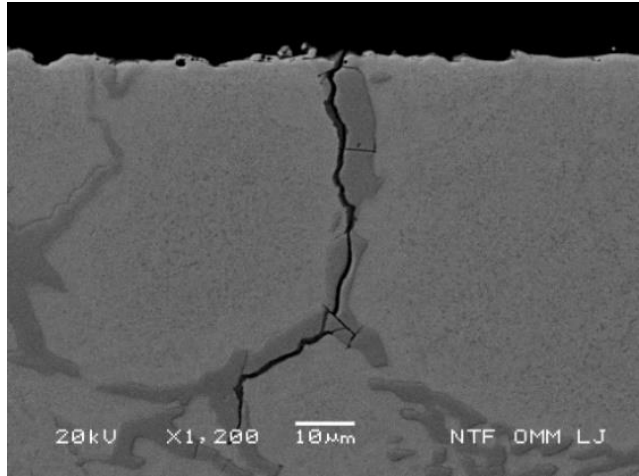

(b)

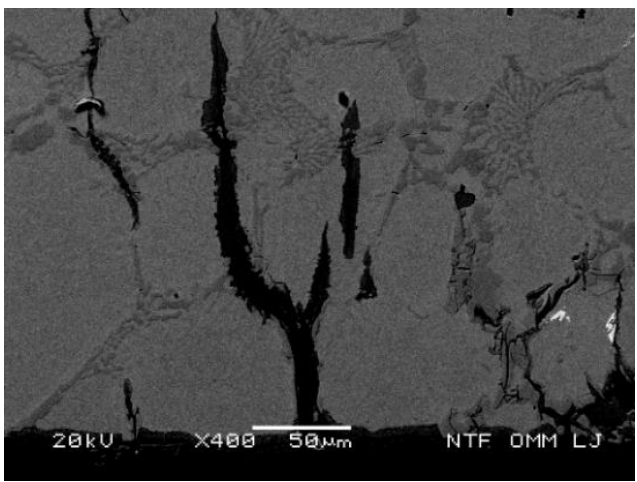

(d)

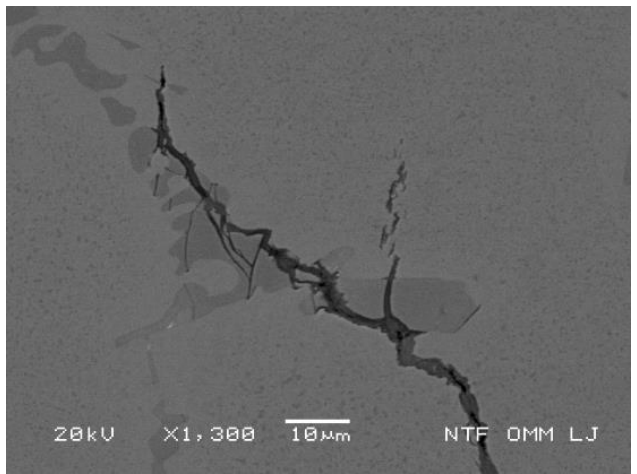

$(\mathbf{f})$

Figure 12. Secondary crack pathways and oxidation behavior; (a) using carbide/matrix interface after 1000 cycles at $500{ }^{\circ} \mathrm{C}$, (b) carbide/matrix crack pathway after 2500 cycles at $500{ }^{\circ} \mathrm{C}$, (c) deviation of oxidation direction after 1000 cycles at $700{ }^{\circ} \mathrm{C}$ from carbide orientation to perpendicular direction in the matrix, (d) deviation of oxidation direction after 2500 cycles at $700{ }^{\circ} \mathrm{C}$, (e) change from carbide pathway to perpendicular direction in the matrix and detail of internal cracks in carbide cluster before crack tip of the primary crack and (f) crack branching from carbide pathway to matrix pathway in the perpendicular direction to the cooled surface.

Oxidation and Branching of Primary Cracks towards Internal Cracks

At lower thermal stress the influence of oxidation during crack growth increases. The crack growth at the test temperature of $700{ }^{\circ} \mathrm{C}$ and a depth of more than $1300 \mu \mathrm{m}$ is shown in Figure $13 \mathrm{a}-\mathrm{d}$, whereby the influence of oxidation during crack growth is increased. In the case shown in Figure 13a (detailed view in Figure 13b), the main crack is divided into three branches. The approach of each of the three individual branches to internal cracks can be observed. This example confirms that the stress field around the internal crack tip influences the direction of oxidation; i.e., the crack growth 
direction is attracted to the influencing stress field. Furthermore, the case in Figure 13c shows the multiple division (oxidation) of the main crack. In general, the main oxidation path is divided into two oxidation branches, which are further individually divided into several branches. In Figure 13c the oxidation direction of the right branch (branch 1) is towards the matrix below the eutectic carbide. As already shown in this area, the $\mathrm{Cr}$ content is reduced, which has a direct effect on the oxidation direction. After the main oxidation tongue has completely covered this area, it begins to branch out into several tongues that approach in a vertical direction perpendicular to the cooled surface. Branch 2 is the left branch in Figure $13 \mathrm{c}$ and is divided into two oxidation branches. The first one grows in the opposite direction of a general crack growth (it grows towards the cooled surface), while the second (lower) branch grows in several directions away from the cooled surface. The later branch is further divided into several smaller, radially oriented branches.

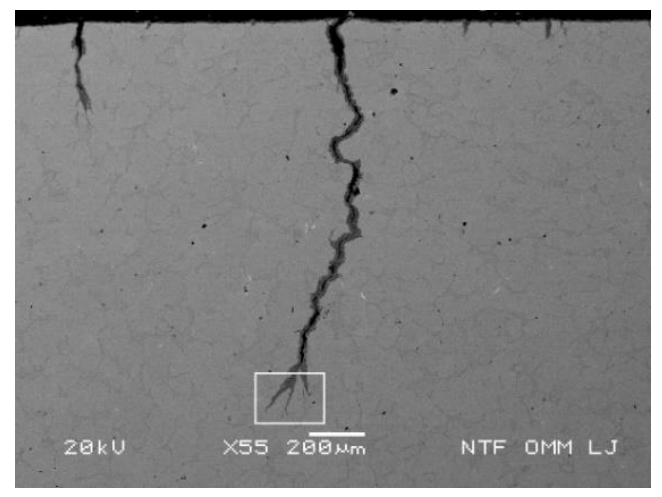

(a)

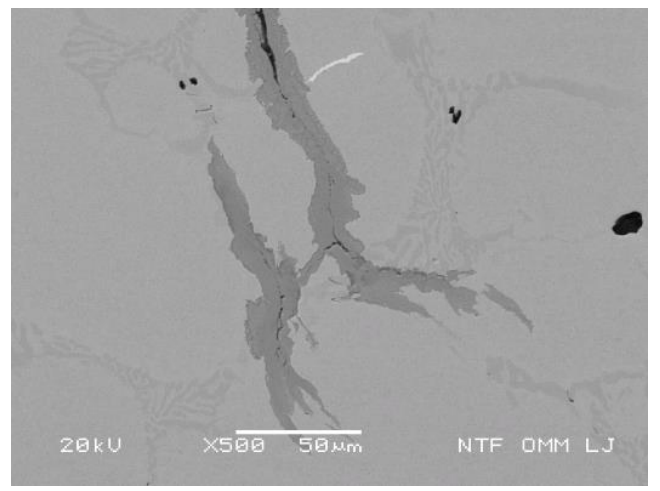

(c)

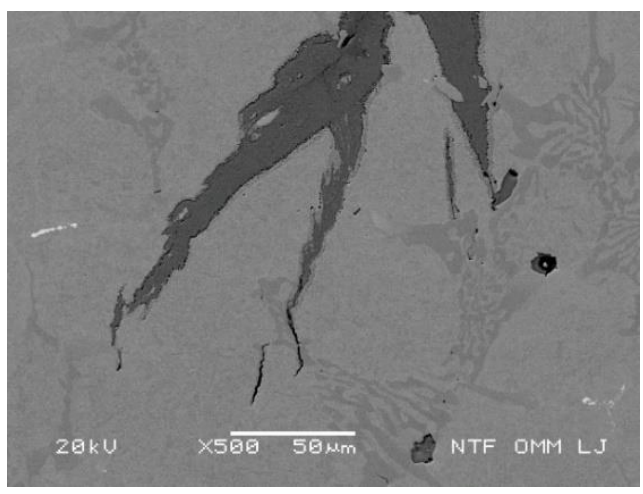

(b)

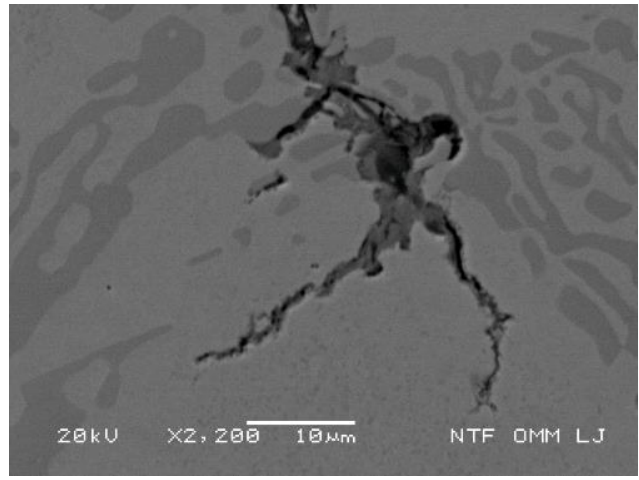

(d)

Figure 13. Influence of oxidation on crack branching: (a) crack exceeding $1300 \mu \mathrm{m}$ with marked area of subfigure b, (b) primary crack branching and individual approaches of oxide branches to internal cracks, (c) branching of the primary crack by oxidation based on low thermal stresses and growth in area with depleted $\mathrm{Cr}$ content and (d) branching of the primary crack in the preferred oxidation direction and growth towards areas with depleted $\mathrm{Cr}$ content in a narrow band adjacent to the eutectic.

At low thermal stresses, the oxidation direction is not emphasized as much as at high thermal stresses. In the latter case, an oxidation branch usually predominates. Figure $13 \mathrm{~d}$ shows the division of the oxidation branch for the test temperature of $600{ }^{\circ} \mathrm{C}$ and 1000 cycles. The formation of oxidation in two sub-brunches occurs after the main crack has passed through the eutectic carbide. A lower $\mathrm{Cr}$ content in the band of about $5 \mu \mathrm{m}$ to the carbide was identified as a major factor in the division into two branches. More detailed observations show that both branches follow the range in the matrix where a lower $\mathrm{Cr}$ is expected. Similarly to the previous observation, the right branch gradually, stepwise, approaches direction perpendicular to the cooled surface at a depth of about $1400 \mu \mathrm{m}$, with a nominal thermal stress of about $400 \mathrm{MPa}$. To describe complete oxidation, one has to consider the variation of 
chemical elements in the matrix near microstructural features such as carbides, since the preferred oxidation pathway may follow changes in matrix composition.

3.3.7. Conditions for an Increased Oxidation Rate of the Matrix along Carbides and Lamellae Eutectics Perpendicular to the Thermal Stresses

In previous subsections it has been shown that areas with depleted $\mathrm{Cr}$ content in the matrix, such as the matrix adjacent to the eutectic and along the primary carbides (see Figure 3), oxidize more rapidly than the carbides themselves (see Figure 4). The observed forms of eutectic carbides vary among lamellae, spheroids and lenticular forms. In the case of eutectic lamellae parallel to the cooled surface, oxidation of eutectic carbide is low due to the low cracking of the parallel lamellar carbides (see Figure 14a,b). A low thickness in the range of 3-6 $\mu \mathrm{m}$ leads to less cracking of the lamellae and a low subsequent oxidation of this eutectic carbide form. The oxidation behavior and crack growth are shown in Figure 10a (detailed view of an area B in Figure 14c). The oxide of the lamellae on the left side is extensive and covers a large area almost perpendicular to the cooled surface. On the other hand, the oxidation of the lamellae on the right side is oriented at an angle of approximately $45^{\circ}$ and at the same time takes the form of a narrow tongue with a length of approximately $140 \mu \mathrm{m}$ (cf. Figure 14c). This behavior was attributed to a reduced $\mathrm{Cr}$ content in the matrix near the eutectic (narrow areas between the lamellar carbides) and to the effective thermal stress applied. Similar observations were made for the eutectic lamellae shown in Figure $14 \mathrm{~d}$, whose inclination is about $70^{\circ}$, and the length of the oxidized tongue is about $120 \mu \mathrm{m}$.

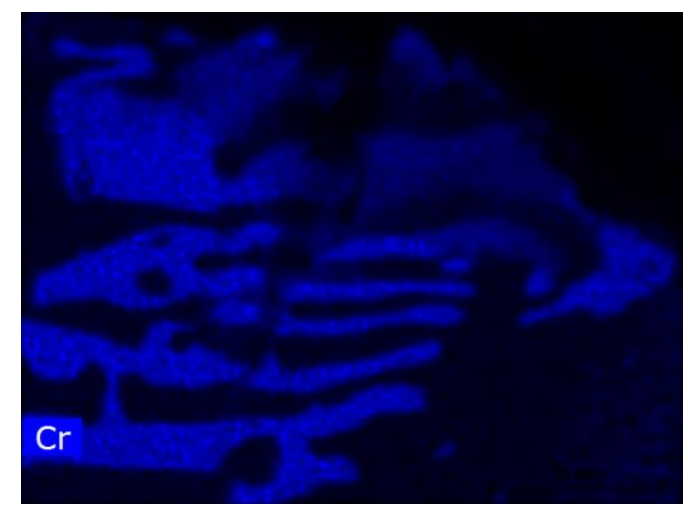

(a)

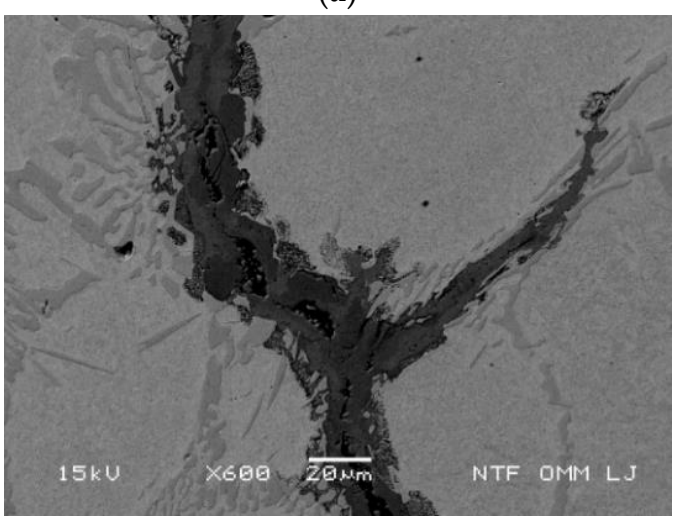

(c)

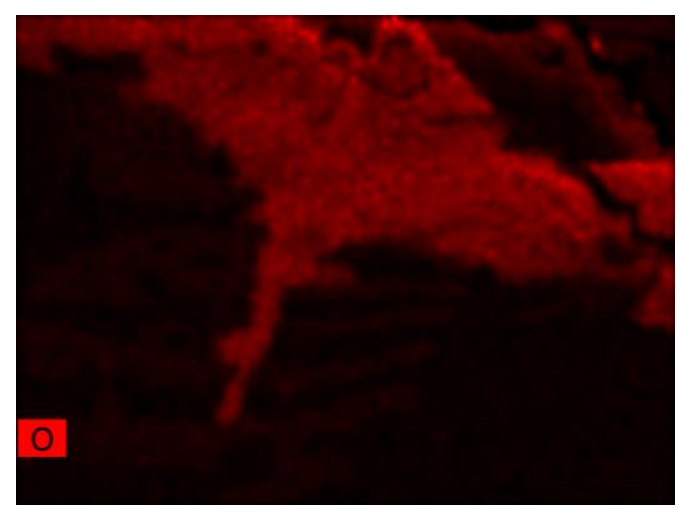

(b)

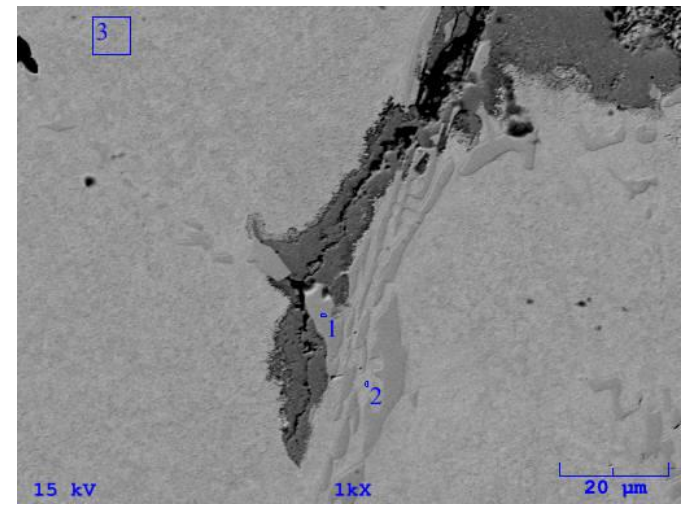

(d)

Figure 14. Oxidation of eutectic lamellae with smaller oxidation area oriented parallel to the cooled surface: (a) Distribution of $\mathrm{Cr}$ and (b) distribution of oxide tongues after 2500 cycles at $700{ }^{\circ} \mathrm{C}$ next to lamellae carbides; (c) detailed view of area A in Figure 10a with long oxidized tongues aligned $45^{\circ}$ to the cooled surface and (d) long tongue next aligned approximately $70^{\circ}$ to the cooled surface. 


\subsubsection{Oxidation Progress of Carbides and Matrix Adjacent to Carbides}

Not only does the $\mathrm{Cr}$ content influence the oxidation, but we also observed different oxidation progressions of the carbides depending on the Mo content. Content of Mo in primary carbides is not uniform and was determined in the range of 3-8 wt. \%. Observations indicate increased oxidation when the Mo content in the carbides is lower (see Table 2 and Figure 2b). Figure 15a,b shows two cases where the oxidation front occurs in areas adjacent to and on the carbides. The carbides in Figure 15a contain a higher Mo content (5 wt. \%) than the carbide shown in Figure 15b, where the measured Mo content was $2.2 \mathrm{wt}$. \%. The comparison of the two oxidation fronts (test temperature of $700{ }^{\circ} \mathrm{C}$ ) clearly shows that at increased Mo (Figure 15a) the oxidation of the carbides takes place in a smaller area along the carbides compared to the area with depleted $\mathrm{Cr}$. Consequently, the oxidation front at these locations is the main focus of attention as far as the oxidation front on carbides is concerned. In the case shown in Figure 15b, where the Mo content in the carbides is lower, the oxidation front is aligned with the carbides and in a narrow $\mathrm{Cr}$ depleted band in the matrix adjacent to the carbides. The observation of differences in oxidation behavior in Figure 15a,b indicates a reduced area of the oxidized material when the Mo content is higher. This points to the dependence of the oxidation intensity of crack tips not only on the depletion of $\mathrm{Cr}$, but also on the Mo content. The observation of differences in oxidation behavior in Figure 15a,b indicates a reduced area of the oxidized carbides when the Mo content is higher.

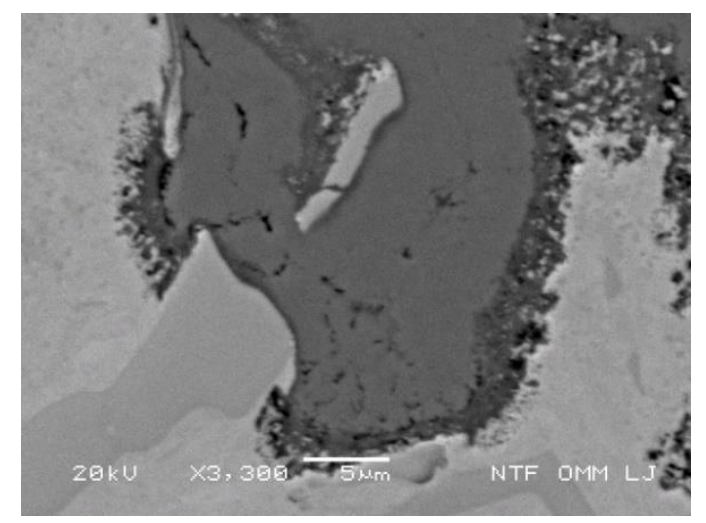

(a)

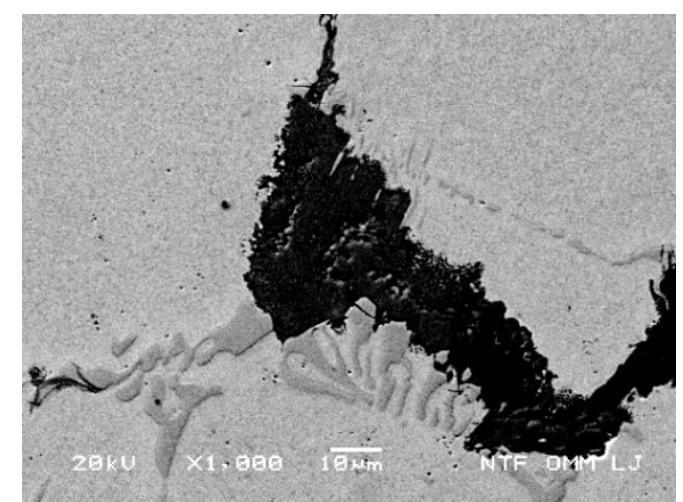

(b)

Figure 15. Oxidized area of matrix adjacent to carbides at test temperature of $700{ }^{\circ} \mathrm{C}$ : (a) approximately 5 wt. \% of Mo in carbides and (b) approximately 2.2 wt. \% of Mo in carbides.

\section{Discussion}

The roller material is constantly exposed to heating and cooling cycles. Due to the cooling water used in rolling mills, some materials show significant surface deterioration not only due to thermal cycles but also due to oxidation. In the available scientific literature, the oxidation phenomena are mainly discussed by classical oxidation studies in humid atmospheres and under isothermal conditions [4,15,22,23,28,34-38]. Since thermal cycles with water cooling stress the material in each cycle, a direct comparison is very difficult. A basic oxidation degradation discussion on a similar material is given in reference [15]. In the present paper, the knowledge of oxidation of high Cr roller material is expanded from initial work on oxidation under thermal fatigue for the same material listed in reference [6]. In addition, the current paper aims to link the oxidation progress with the level of thermal stress applied.

In accordance with the literature $[6,7,15,39,45]$, oxidation of larger eutectic carbides under the cooled surface in combination with the crack growth direction using primary carbide paths leads to fusion of the oxidized region and consequently to early spalling and chipping of the fused regions from the surface layer. A novel contribution of this work is the division of the applied thermal stress based on the stress level into stages with observed similar crack growth and oxidation degradation of 
the roller material. The contribution of oxidation to crack growth is conditionally divided into three different stages with respect to thermal stress and primary crack growth progress:

(i) The first stage, in which the applied thermal stresses are high, is characterized by processes of cracking and crushing of carbides related to crack growth. The crack growth follows the carbide pathway, with oxidation playing a less relevant role. However, oxidation still causes an increase in stress at the crack tips.

(ii) Second stage, in which the effective thermal stress is medium, shows crack growth by cracking and crushing of carbides and internal oxidation of cracks. Internal crack oxidation leads to increased stress at the crack tip and reduced strength of the material around the crack tip. Cracks mainly follow the carbide path.

(iii) The third stage, in which the effective thermal stresses are low, is characterized by crack growth by fusion of internal cracks and the main crack. Important is the increased role of oxidation; i.e., crack growth takes a favorable oxidation direction perpendicular to the maximum thermal stress.

Oxidation allows changes in crack growth direction; i.e., from carbide path to path through the matrix. The inclination angle to the cooled surface and the straightness of the cracks increase, and oxidation of the carbide/matrix interface is common. The oxidation growth characteristic of secondary cracks is similar to the third stage of primary crack growth.

Thermal stress; shape and size of the eutectic, contents of $\mathrm{Cr}$ in the matrix and eutectic carbides, orientation of the eutectic lamellae (perpendicular to the cooled surface), occurrence of cracks in eutectic carbides and temperature accelerate the oxidation of the matrix. The oxidation progress of carbides and the matrix adjacent to carbides depends on the local chemical composition. The oxidation intensity of crack tips depends not only on the depletion of $\mathrm{Cr}$, but also on the Mo content. If the Mo content in the carbides is lower, the oxidation front will align along the carbides and the oxidation rate is expected to accelerate. The results obtained confirm that the matrix generally oxidizes faster. As shown in Figure $15 b$, carbides can oxidize at a similar rate to the matrix due to local variations in chemical composition, especially Mo content. In some cases, carbides could oxidize faster than the matrix, depending on the local chemical composition, which complements the observations of Kim et al. [34]. Large oxidation tongues in the present study contrast with oxidation studies $[4,15,22,23,28,34-38]$ and tribological tests $[3,9-11,14,16,25,26,33,35,39-57]$. This is attributed to test conditions where thermal cycles play an important role in O diffusion and confirms the theory of Lao et al. [27] that the condition under isothermal testing in the highly plastic deformed region during sliding wear is not comparable to the behavior during hot rolling.

\section{Conclusions}

The oxidation behavior during crack growth was characterized on specimens after thermal fatigue tests of $\mathrm{Cr} 12(1.7 \mathrm{C}, 11.3 \mathrm{Cr}, 1.9 \mathrm{Ni}$ and $1.2 \mathrm{Mo})$ roller steel in the temperature range of $500-700{ }^{\circ} \mathrm{C}$. The fatigue tests were interrupted after 200, 500, 1000 and 2500 thermal cycles and examined by electron microscopy for degradation mechanisms, crack growth and oxidation behavior. Observations of the oxidation behavior are linked to the calculated magnitude of thermal stress, the properties of the matrix material and the carbides as well as the test temperature. The following conclusions can be drawn from the results obtained:

- The orientation of the carbides embedded in the microstructure is varied, which in combination with the oxidation behavior and the thermal stress influence crack growth.

- Thermal stress depends on the test temperature and the distance from the cooled surface. The FEM simulations were used to determine the change in thermal stress acting through the sample wall and show a strong correlation between temperature and stress value. An effective thermal stress of more than $900 \mathrm{MPa}$ was estimated to be high. The low effective thermal stress is below $700 \mathrm{MPa}$. Values between low and high were assumed as medium thermal stress.

- Areas with depleted $\mathrm{Cr}$ content in the vicinity of eutectic carbides and within a narrow band adjacent to the primary carbides were observed. Areas with reduced $\mathrm{Cr}$ are more susceptible 
to oxidation. This applies to material surrounding eutectic carbide and band adjacent the primary carbides.

- The oxidation behavior is temperature dependent and influences thermal stress as well as carbide and matrix properties. The oxide area grows with higher temperature and thermal stress. The oxidation mechanism is based on diffusion growth, and the oxidation rate of the matrix adjacent to the carbides is generally higher than in the oxidation of carbides. Due to the variation of the local chemical composition, carbides could oxidize faster in special cases.

- The direction of oxidation in the matrix is determined by the direction of the effective thermal stress in combination with the crack tip stress. The oxidation of the eutectic carbides located below the surface is associated with the cracking of eutectic carbides and the formation of cracks from the surface to eutectic carbides, which enabled the diffusion of oxygen in the crack canal.

- Cracking of eutectic carbides is accelerated by thermal stresses, which accelerate the oxidation rates of carbides. The influence of the Mo content on the oxidation of carbides and consequently on crack growth was observed. An increased content of Mo in carbides slows down oxidation around the carbides.

Author Contributions: Conceptualization, D.B. and M.T.; formal analysis, D.B.; investigation, D.B., M.G. and M.T.; resources, G.K.; supervision, G.K.; validation, G.K. and M.T.; visualization, D.B.; writing-original draft, D.B.; writing-review and editing, D.B., M.G. and M.T. All authors have read and agreed to the published version of the manuscript.

Funding: We are grateful to the Slovenian Research Agency (ARRS) for funding under program grants P2-0344 and P2-0268.

Acknowledgments: The authors would like to thank Peter Fajfar and Matej Drobne for the many useful discussions and Valji d.o.o. (Štore, Slovenija) for providing the material used in this study. The research assistance of Andrej Penko and Samo Smolej is gratefully appreciated.

Conflicts of Interest: The authors declare no conflict of interest. The funders had no role in the design of the study; in the collection, analyses, or interpretation of data; in the writing of the manuscript, or in the decision to publish the results.

\section{References}

1. Spuzic, S.; Strafford, K.N.; Subramanian, C.; Savage, G. Wear of hot rolling mill rolls: An overview. Wear 1994, 176, 261-271. [CrossRef]

2. Bataille, C.; Luc, E.; Bigerelle, M.; Deltombe, R.; Dubar, M. Rolls wear characterization in hot rolling process. Tribol. Int. 2016, 100, 328-337. [CrossRef]

3. Hanlon, D.N.; Rainforth, W.M. The rolling sliding wear response of conventionally processed and spray formed high speed steel at ambient and elevated temperature. Wear 2003, 255, 956-966. [CrossRef]

4. Zamri, W.F.H.; Kosasih, P.B.; Tieu, A.K.; Zhu, Q.; Zhu, H. Variations in the microstructure and mechanical properties of the oxide layer on high speed steel hot rolling work rolls. J. Mater. Process. Technol. 2012, 212, 2597-2608. [CrossRef]

5. Bombač, D.; Kugler, G.; Markoli, B.; Terčelj, M. Hot work roller surface layer degradation progress during thermal fatigue in the temperature range 500-700 ${ }^{\circ} \mathrm{C}$. Int. J. Fatigue 2017, 104, 355-365. [CrossRef]

6. Bombač, D.; Gintalas, M.; Kugler, G.; Terčelj, M. Thermal fatigue behaviour of Fe-1.7C-11.3Cr-1.9Ni-1.2Mo roller steel in temperature range $500-700^{\circ} \mathrm{C}$. Int. J. Fatigue 2019, 121, 98-111. [CrossRef]

7. Colás, R.; Ramírez, J.; Sandoval, I.; Morales, J.C.; Leduc, L.A. Damage in hot rolling work rolls. Wear 1999, 230, 56-60. [CrossRef]

8. Tieu, A.K.; Zhu, Q.; Zhu, H.; Lu, C. An investigation into the tribological behaviour of a work roll material at high temperature. Wear 2011, 273, 43-48. [CrossRef]

9. Choi, J.-W.; Kim, D. Mechanisms of Surface Deterioration of High-Ni Grain Roll for Hot Strip Rolling. ISIJ Int. 1999, 39, 823-828. [CrossRef]

10. Lee, J.H.; Oh, J.C.; Park, J.W.; Lee, H.C.; Lee, S. Effects of Tempering Temperature on Wear Resistance and Surface Roughness of a High Speed Steel Roll. ISIJ Int. 2001, 41, 859-865. [CrossRef] 
11. Kato, O.; Yamamoto, H.; Ataka, M.; Nakajima, K. Mechanisms of Surface Deterioration of Roll for Hot Strip Rolling. ISIJ Int. 1992, 32, 1216-1220. [CrossRef]

12. Deng, G.Y.; Zhu, H.T.; Tieu, A.K.; Su, L.H.; Reid, M.; Zhang, L.; Wei, P.T.; Zhao, X.; Wang, H.; Zhang, J.; et al. Theoretical and experimental investigation of thermal and oxidation behaviours of a high speed steel work roll during hot rolling. Int. J. Mech. Sci. 2017, 131-132, 811-826. [CrossRef]

13. Deng, G.Y.; Zhu, Q.; Tieu, K.; Zhu, H.T.; Reid, M.; Saleh, A.A.; Su, L.H.; Ta, T.D.; Zhang, J.; Lu, C.; et al. Evolution of microstructure, temperature and stress in a high speed steel work roll during hot rolling: Experiment and modelling. J. Mater. Process. Technol. 2017, 240, 200-208. [CrossRef]

14. Delaunois, F.; Stanciu, V.I.; Sinnaeve, M. Resistance to High-Temperature Oxidation and Wear of Various Ferrous Alloys Used in Rolling Mills. Metall. Mater. Trans. A 2018, 49, 822-835. [CrossRef]

15. Molinari, A.; Straffelini, G.; Tomasi, A.; Biggi, A.; Corbo, G. Oxidation behaviour of ledeburitic steels for hot rolls. Mater. Sci. Eng., A 2000, 280, 255-262. [CrossRef]

16. Joos, O.; Boher, C.; Vergne, C.; Gaspard, C.; Nylen, T.; Rezaï-Aria, F. Assessment of oxide scales influence on wear damage of HSM work rolls. Wear 2007, 263, 198-206. [CrossRef]

17. Yang, W.; Huang, Y.; Zhou, Q.; Wang, J.; Jin, X.; Keer, L.M. Parametric study on stressed volume and its application to the quantification of rolling contact fatigue performance of heterogeneous material. Tribol. Int. 2017, 107, 221-232. [CrossRef]

18. Hamraoui, M. Thermal behaviour of rollers during the rolling process. Appl. Therm. Eng. 2009, 29, $2386-2390$. [CrossRef]

19. Mercado-Solis, R.D.; Beynon, J.H. Simulation of thermal fatigue in hot strip mill work rolls. Scand. J. Metall. 2005, 34, 175-191. [CrossRef]

20. Belzunce, F.J.; Ziadi, A.; Rodriguez, C. Structural integrity of hot strip mill rolling rolls. Eng. Fail. Anal. 2004, 11, 789-797. [CrossRef]

21. Günen, A.; Kanca, E.; Karakaş, M.S.; Koç, V.; Gök, M.S.; Kanca, Y.; Çürük, A.; Demir, M. High temperature wear behavior of the surface-modified externally cooled rolls. Surf. Coat. Technol. 2018, 348, 130-141. [CrossRef]

22. Zhu, Q.; Zhu, H.T.; Tieu, A.K.; Reid, M.; Zhang, L.C. In-situ investigation of oxidation behaviour in high-speed steel roll material under dry and humid atmospheres. Corros. Sci. 2010, 52, 2707-2715. [CrossRef]

23. Ramírez-Ramírez, J.H.; Colás, R.; Garza-Montes-de-Oca, N.F. High Temperature Oxidation of a Work Roll Grade High-Chromium White Cast Iron. J. Iron. Steel Res. Int. 2013, 20, 122-129. [CrossRef]

24. Garza-Montes-de-Oca, N.F.; Colás, R.; Rainforth, W.M. On the damage of a work roll grade high speed steel by thermal cycling. Eng. Fail. Anal. 2011, 18, 1576-1583. [CrossRef]

25. Kang, Y.J.; Oh, J.C.; Lee, H.C.; Lee, S. Effects of carbon and chromium additions on the wear resistance and surface roughness of cast high-speed steel rolls. Metall. Mater. Trans. A 2001, 32, 2515-2525. [CrossRef]

26. Pellizzari, M.; Molinari, A.; Straffelini, G. Tribological behaviour of hot rolling rolls. Wear 2005, 259, 1281-1289. [CrossRef]

27. Lao, Y.; Du, H.; Xiong, T.; Wang, Y. Evolution Behaviors of Oxides in Severely Plastic Deformed Region of AISI 52100 Steel during Dry Sliding Wear. J. Mater. Sci. Technol. 2017, 33, 330-337. [CrossRef]

28. Cho, S.; Jo, I.; Kim, H.; Kwon, H.-T.; Lee, S.-K.; Lee, S.-B. Effect of TiC addition on surface oxidation behavior of SKD11 tool steel composites. Appl. Surf. Sci. 2017, 415, 155-160. [CrossRef]

29. Min, Y.; Jens, B.; Wu, X.; Xu, L. Oxidation and Thermal Fatigue Behaviors of Two Type Hot Work Steels during Thermal Cycling. J. Iron. Steel Res. Int. 2013, 20, 90-97. [CrossRef]

30. Molinari, A.; Pellizzari, M.; Tremea, A.; Biggi, A.; Corbo, G. Effect of matrix microhardness on thermal fatigue behaviour of spincast high speed steels for hot rolls. Mater. Sci. Technol. 2005, 21, 352-356. [CrossRef]

31. Molinari, A.; Tremea, A.; Pellizzari, M.; Biggi, A.; Corbo, G. High speed steels for hot rolls with improved impact and thermal fatigue resistance. Mater. Sci. Technol. 2002, 18, 1574-1580. [CrossRef]

32. Pellizzari, M.; Cescato, D.; Flora, M.G. De Hot friction and wear behaviour of high speed steel and high chromium iron for rolls. Wear 2009, 267, 467-475. [CrossRef]

33. Oksanen, V.; Valtonen, K.; Andersson, P.; Vaajoki, A.; Laukkanen, A.; Holmberg, K.; Kuokkala, V.T. Comparison of laboratory rolling-sliding wear tests with in-service wear of nodular cast iron rollers against wire ropes. Wear 2015, 340-341, 73-81. [CrossRef]

34. Kim, H.-H.; Lim, J.-W.; Lee, J.-J. Oxidation Behavior of High-speed Steels in Dry and Wet Atmospheres. ISIJ Int. 2003, 43, 1983-1988. [CrossRef] 
35. Pellizzari, M.; Molinari, A.; Cescato, D.; Tremea, A.; Corbo, G.; Biggi, A. Wear and friction behaviour of high chromium iron and high speed steels for hot rolls. In Proceedings of the International Conference on Abrasion 2005, Sao Paulo, Brazil, 14-17 August 2005; Volume 2005, pp. 189-198.

36. Monteiro, M.J.; Saunders, S.R.J.; Rizzo, F.C. The Effect of Water Vapour on the Oxidation of High Speed Steel, Kinetics and Scale Adhesion. Oxid. Met. 2011, 75, 57-76. [CrossRef]

37. Garza-Montes-de-Oca, N.F.; Colás, R.; Rainforth, W.M. High Temperature Oxidation of a Work Roll Grade High Speed Steel. Oxid. Met. 2011, 76, 451. [CrossRef]

38. Molinari, A.; Pellizzari, M.; Biggi, A.; Corbo, G.; Tremea, A. Primary carbides in spincast HSS for hot rolls and their effect on the oxidation behaviour. In Proceedings of the Proceedings 6th International Tooling Conference, Karlstadt, Germany, 10-13 September 2002; pp. 365-377.

39. Garza-Montes-de-Oca, N.F.; Rainforth, W.M. Wear mechanisms experienced by a work roll grade high speed steel under different environmental conditions. Wear 2009, 267, 441-448. [CrossRef]

40. Li, C.; Liu, X.; Wang, G. New Method for Evaluating Thermal Wear of Rolls in Rolling Process. J. Iron. Steel Res. Int. 2008, 15, 52-55. [CrossRef]

41. Pellizzari, M.; Flora, M.G. De Influence of laser hardening on the tribological properties of forged steel for hot rolls. Wear 2011, 271, 2402-2411. [CrossRef]

42. Sano, Y.; Hattori, T.; Haga, M. Characteristics of High-carbon High Speed Steel Rolls for Hot Strip Mill. ISIJ Int. 1992, 32, 1194-1201. [CrossRef]

43. Park, J.W.; Lee, H.C.; Lee, S. Composition, microstructure, hardness, and wear properties of high-speed steel rolls. Metall. Mater. Trans. A 1999, 30, 399-409. [CrossRef]

44. Lundberg, S.-E.; Gustafsson, T. The influence of rolling temperature on roll wear, investigated in a new high temperature test rig. J. Mater. Process. Technol. 1994, 42, 239-291. [CrossRef]

45. Hanlon, D.N.; Rainforth, W.M.; Sellars, C.M. The rolling/sliding wear response of conventionally processed and spray formed high chromium content cast iron at ambient and elevated temperature. Wear 1999, 225-229, 587-599. [CrossRef]

46. Xu, L.; Fan, X.; Wei, S.; Liu, D.; Zhou, H.; Zhang, G.; Zhou, Y. Microstructure and wear properties of high-speed steel with high molybdenum content under rolling-sliding wear. Tribol. Int. 2017, 116, 39-46. [CrossRef]

47. Xu, L.; Xing, J.; Wei, S.; Zhang, Y.; Long, R. Investigation on wear behaviors of high-vanadium high-speed steel compared with high-chromium cast iron under rolling contact condition. Mater. Sci. Eng. A 2006, 434, 63-70. [CrossRef]

48. Kang, M.; Suh, Y.; Oh, Y.-J.; Lee, Y.-K. The effects of vanadium on the microstructure and wear resistance of centrifugally cast Ni-hard rolls. J. Alloys Compd. 2014, 609, 25-32. [CrossRef]

49. Mercado-Solis, R.D.; Talamantes-Silva, J.; Beynon, J.H.; Hernandez-Rodriguez, M.A.L. Modelling surface thermal damage to hot mill rolls. Wear 2007, 263, 1560-1567. [CrossRef]

50. Xu, L.; Wei, S.; Xing, J.; Long, R. Effects of carbon content and sliding ratio on wear behavior of high-vanadium high-speed steel (HVHSS) under high-stress rolling-sliding contact. Tribol. Int. 2014, 70, 34-41. [CrossRef]

51. Vergne, C.; Boher, C.; Gras, R.; Levaillant, C. Influence of oxides on friction in hot rolling: Experimental investigations and tribological modelling. Wear 2006, 260, 957-975. [CrossRef]

52. Hokkirigawa, K.; Kato, T.; Fukuda, T.; Shinooka, M. Analysis of Sliding Wear Mechanism of Oxide Films on Hot Roll Surfaces Based On In-Situ Observation of Wear Process by the CCD Microscope Tribosystem. J. Jpn. Soc. Tribol. 1997, 42, 777-784.

53. Zhu, H.; Zhu, Q.; Tieu, A.K.; Kosasih, B.; Kong, C. A simulation of wear behaviour of high-speed steel hot rolls by means of high temperature pin-on-disc tests. Wear 2013, 302, 1310-1318. [CrossRef]

54. Ren, X.; Fu, H.; Xing, J.; Yi, Y. Research on high-temperature dry sliding friction wear behavior of CaTi modified high boron high speed steel. Tribol. Int. 2019, 132, 165-176. [CrossRef]

55. Hao, L.; Wu, H.; Wei, D.; Cheng, X.; Zhao, J.; Luo, S.; Jiang, L.; Jiang, Z. Wear and friction behaviour of high-speed steel and indefinite chill material for rolling ferritic stainless steels. Wear 2017, 376-377, 1580-1585. [CrossRef] 
56. Torres, H.; Varga, M.; Widder, F.; Cihak-Bayr, U.; Viskovic, O.; Ripoll, M.R. Experimental simulation of high temperature sliding contact of hot rolled steel. Tribol. Int. 2016, 93, 745-754. [CrossRef]

57. Savage, G.; Boelen, R.; Horti, A.; Morikawa, H.; Tsujimoto, Y. Hot wear testing of roll alloys. In Proceedings of the Mechanical Working and Steel Processing Conference Proceedings, Cleveland, OH, USA, 13-16 October 1996; pp. 333-340. 